\title{
Overexpression of Laccaria bicolor aquaporin JQ585595 alters root water transport properties in ectomycorrhizal white spruce (Picea glauca) seedlings
}

\author{
Hao Xu' ${ }^{1}$, Minna Kemppainen ${ }^{2}$, Walid El Kayal ${ }^{3}$, Seong Hee Lee ${ }^{1}$, Alejandro G. Pardo ${ }^{2}$, Janice E. K. Cooke ${ }^{3}$ and \\ Janusz J. Zwiazek ${ }^{1}$ \\ ${ }^{1}$ Department of Renewable Resources, University of Alberta, Edmonton, AB T6G 2E3, Canada; ${ }^{2}$ Laboratorio de Micología Molecular, Departamento de Ciencia y Tecnología, Universidad \\ Nacional de Quilmes and Consejo Nacional de Investigaciones Científicas y Técnicas (CONICET), Bernal, Argentina; ${ }^{3}$ Department of Biological Sciences, University of Alberta, Edmonton, \\ AB T6G 2E9, Canada
}

Author for correspondence: Janusz J. Zwiazek

Tel: +17804922358

Email: janusz.zwiazek@ualberta.ca

Received: 3 August 2014

Accepted: 27 August 2014

New Phytologist (2014)

doi: 10.1111/nph.13098

Key words: cell hydraulic conductivity, Laccaria bicolor, mycorrhizal fungal aquaporins, Picea glauca, plasma membrane intrinsic protein, root hydraulic conductivity, water transport.

\section{Summary}

- The contribution of hyphae to water transport in ectomycorrhizal (ECM) white spruce (Picea g/auca) seedlings was examined by altering expression of a major water-transporting aquaporin in Laccaria bicolor.

- Picea glauca was inoculated with wild-type (WT), mock transgenic or L. bicolor aquaporin JQ585595-overexpressing (OE) strains and exposed to root temperatures ranging from 5 to $20^{\circ} \mathrm{C}$ to examine the root water transport properties, physiological responses and plasma membrane intrinsic protein (PIP) expression in colonized plants.

- Mycorrhization increased shoot water potential, transpiration, net photosynthetic rates, root hydraulic conductivity and root cortical cell hydraulic conductivity in seedlings. At $20^{\circ} \mathrm{C}$, OE plants had higher root hydraulic conductivity compared with WT plants and the increases were accompanied by higher expression of P. glauca PIP GQ03401_M18.1 in roots. In contrast to WT L. bicolor, the effects of OE fungi on root and root cortical cell hydraulic conductivities were abolished at 10 and $5^{\circ} \mathrm{C}$ in the absence of major changes in the examined transcript levels of $P$. glauca root PIPs.

- The results provide evidence for the importance of fungal aquaporins in root water transport of mycorrhizal plants. They also demonstrate links between hyphal water transport, root aquaporin expression and root water transport in ECM plants.

\section{Introduction}

Ectomycorrhizal (ECM) fungi absorb water and nutrients through extensive extraradical hyphal networks, transporting these resources to the mantle and Hartig net where resources are exchanged with the host plant root (Agerer, 2001). Processes involved in water uptake by mycorrhizal plants have received less attention than nutrient acquisition. Improved plant water relations have been frequently attributed to ECM (Plamboeck et al., 2007; Lehto \& Zwiazek, 2011) and arbuscular mycorrhizas (AM) (Uehlein et al., 2007; Bárzana et al., 2012). The effects of mycorrhizal associations often include increased root hydraulic conductivity (Muhsin \& Zwiazek, 2002a,b; Marjanović et al., 2005), which has been attributed to increased apoplastic (Nylund, 1987; Muhsin \& Zwiazek, 2002a; Bárzana et al., 2012) and transmembrane water transport (Marjanović et al., 2005; Porcel et al., 2006; Aroca et al., 2007; Uehlein et al., 2007; Lee et al., 2010). The contribution of extraradical fungal hyphae to root water transport can be significant, as evidenced by decreased root hydraulic conductance following removal of these hyphae
(Muhsin \& Zwiazek, 2002b). Increased relative apoplastic flow in mycorrhizal plants has also been determined by use of apoplastic tracer dye (Bárzana et al., 2012) and inhibitors of aquaporin activity (Muhsin \& Zwiazek, 2002a; Bárzana et al., 2012). However, use of apoplastic tracer dyes and aquaporin inhibitors can be problematic because they also potentially affect hyphal water transport.

Mycorrhizal associations have been reported to increase hydraulic conductivity of root cortical cells (Lee et al., 2010) and alter the expression of root aquaporins in AM and ECM plants (Marjanović etal., 2005; Porcel etal., 2006; Aroca et al., 2007; Uehlein et al., 2007; Dietz et al., 2011; Giovannetti et al., 2012; Navarro-Ródenas et al., 2013). Plant aquaporins are categorized into PIP (plasma membrane intrinsic protein), TIP (tonoplast intrinsic protein), NIP (nodulin-26 like intrinsic protein), SIP (small intrinsic proteins) and XIP (X intrinsic proteins) subfamilies, based on subcellular localization and transport capacities (Maurel et al., 2008). PIPs play a crucial role in facilitating water transport and regulating root (Javot \& Maurel, 2002; Aroca et al., 2012; Gambetta et al., 2013) and leaf (Maurel et al., 2008; 
Prado \& Maurel, 2013) hydraulic conductivity. Their expression and post-translational modifications are sensitive to various environmental factors (Javot \& Maurel, 2002; Maurel et al., 2008; Gambetta et al., 2013). The relative contributions of transmembrane and apoplastic water transport pathways in mycorrhizal roots may partly explain the reported lack of effect of mycorrhization on host plant root water flow properties (Coleman et al., 1990; Nardini et al., 2000; Calvo-Polanco et al., 2008; Siemens \& Zwiazek, 2008; Yi et al., 2008).

Delineating the precise pathways for water transport from the fungal partner to the host roots in mycorrhizal associations remains a challenge. Some studies support the view that hydrophobic fungal cell walls in the mantle may block the apoplastic water pathway and hinder root water uptake (Duddridge et al., 1980; Unestam \& Sun, 1995), whereas others argue that fungal hyphae are more likely to form a water transport highway for plant roots, which substantially increases water availability to the roots (Khalvati et al., 2005; Allen, 2007; Egerton-Warburton et al., 2007; Lehto \& Zwiazek, 2011). Because water can be transported in the cell walls of hydrophilic fungi, including Laccaria bicolor (Weatherley, 1982; Lehto \& Zwiazek, 2011), it could be argued that this route offers the least resistance and thus could be the predominant pathway for water transport to the root cortex. However, the advantages of a symplastic pathway for hyphal water transport include the possibility of hydraulic regulation by fungal aquaporins as water enters and subsequently leaves the hyphae.

In this study, we addressed the question of the contribution of aquaporin-mediated transport in mycorrhizal fungal hyphae to water transport of the host plant. Fungal aquaporins have been described from several fungal taxa, and can be classified into four distinct groups: orthodox fungal water channels, fungal aquaglyceroporins, facultative fungal aquaporins and fungal XIPs (Dietz et al., 2011; Xu et al., 2013). Recent studies have demonstrated the capacity for transport of water and other small molecules by several aquaporins from ECM and AM fungi (Dietz et al., 2011; Navarro-Ródenas etal., 2012; Li etal., 2013), which may play multiple roles in plant-fungal interactions (Maurel \& Plassard, 2011). In L. bicolor strain S238N, five aquaporin genes heterologously expressed in Xenopus laevis oocytes showed strong to moderate water transport capacity; some of these were also permeable to urea, glycerol and ammonia (Dietz et al., 2011). TcAQP1 from the hypogeous mycorrhizal desert truffle (Terfezia claveryi) also showed water and $\mathrm{CO}_{2}$ transport capacity (Navarro-Ródenas et al., 2013), whereas GintAQPF1 and GintAQPF2 from the AM species Glomus intraradices showed significant water permeability (Li et al., 2013). The expression of these fungal aquaporins could be altered by mycorrhization or abiotic cues (Dietz et al., 2011; Li et al., 2013; Navarro-Ródenas et al., 2013), suggesting their involvement in water transport of the mycorrhizal partners.

One means to assess the relative significance of the different pathways for water movement in mycorrhizal plants is to alter the aquaporin-mediated water transport properties of the mycorrhizal fungus partner. Accordingly, we selected the aquaporinencoding JQ585595 (protein ID AFJ15558.1) from L. bicolor strain UAMH8232 for its high water transport capacity and high transcript abundance, and generated transgenic L. bicolor overexpressing JQ585595 to test the role of this fungal aquaporin in facilitating water transport in ectomycorrhizal white spruce (Picea glauca [Moench] Voss). P. glauca seedlings inoculated with wildtype (WT), JQ585595-overexpressing (OE) and mock-transformed strains were examined for the effect of these fungal genotypes on water transport properties of the host plant. We tested the hypothesis that root hydraulic conductivity of mycorrhizal plants would be enhanced by overexpression of the L. bicolor aquaporin, reflecting the increased contribution of water transport through fungal hyphae to water transport of the mycorrhizal root system.

\section{Materials and Methods}

\section{Cloning and in silico analysis of L. bicolor aquaporin genes}

Laccaria bicolor (Maire) P.D. Orton strain UAMH8232 (University of Alberta Microfungus Collection) mycelia were grown on solid modified Melin-Norkans (MMN) medium (Pham et al., 2004) at $20^{\circ} \mathrm{C}$ with cellophane placed on the surface for $3 \mathrm{wk}$ before mycelia were harvested and immediately frozen in liquid nitrogen. Mycelia were ground in liquid nitrogen using a mortar and pestle. Total RNA was extracted using the RNeasy Plant Mini Kit (Qiagen), and used for first strand cDNA synthesis (Superscript II; Life Technologies, Carlsbad, CA, USA). Full-length L. bicolor UAMH8232 cDNAs corresponding to five of the seven L. bicolor aquaporins reported by Dietz et al. (2011) were amplified using gene-specific primers designed using L. bicolor strain S238N sequence information (Supporting Information Table S1), and ligated into pGEM-T Easy (Promega). Sequences were confirmed by Sanger sequencing, and have been deposited in GenBank (accession numbers JQ585592-JQ585597).

Protein transmembrane secondary structure and subcellular localization was predicted using TMHMM2.0 (Krogh etal., 2001) and Target P (Emanuelsson et al., 2000), respectively. Sequence alignment and phylogenetic analysis was conducted using ClustalW 2.1 (Larkin etal., 2007) and MEGA 5.2.1 (Felsenstein, 1985; Saitou \& Nei, 1987; Tamura et al., 2011).

\section{Functional analysis of $L$. bicolor aquaporins}

Full-length cDNAs were sub-cloned into the multiple cloning site of pXT7 containing the T7 promoter and the $5^{\prime}$ and $3^{\prime}$ UTR of the X. laevis $\beta$-globin gene (Dominguez et al., 1995), between the restriction sites $X h o \mathrm{I}$ and SpeI. Insertion orientation was determined by sequencing, then the expression vector was linearized at the NdeI site located downstream of the Xenopus $\beta$-globin gene. The linearized vector was used for in vitro synthesis of capped RNA (cRNA) using T7 RNA polymerase (mMESSAGE mMACHINE T7 kit; Ambion).

For the X. laevis oocyte swelling assay, healthy Stage V-VI oocytes were treated with collagenase and potassium phosphate (Cao et al., 1992). Ten ng of cRNA or nuclease-free water (as the negative control) was microinjected into each oocyte using an automatic nanoliter injector (Nanoject II; Drummond Scientific, 
Broomall, PA, USA). After incubation in $200 \mathrm{mOsmol}\left(\mathrm{kg}^{-1}\right.$ $\left.\mathrm{H}_{2} \mathrm{O}\right)$ modified Barth's solution (MBM) in scintillation vials at $18^{\circ} \mathrm{C}$ for $48 \mathrm{~h}$, each injected oocyte was transferred into MBM in one well of a four-well Petri dish and viewed under the $\times 4$ objective of an Olympus compound microscope. An initial image was taken with an Olympus QCapture digital camera; upon transfer of an oocyte into a well containing $D=0.2$ hypotonic MBM ( 40 mOsmol kg ${ }^{-1} \mathrm{H}_{2} \mathrm{O}$ ), serial images were captured at 10 -s intervals for $3 \mathrm{~min}$ to track changes in oocyte volume due to water influx. The diameter and surface area of oocytes were analyzed using ImageJ (v1.44o; Schneider et al., 2012). The initial transmembrane volume flux and osmotic water permeability coefficiency $\left(P_{\mathrm{f}}\right)$ were calculated based on Zhang \& Verkman (1991) to represent the water permeability of the oocytes injected with cRNAs of each putative aquaporin.

\section{Generation of transgenic L. bicolor strains}

Transgenic Laccaria strains overexpressing JQ585595 were generated using the $\mathrm{pHg} / \mathrm{pSILBA} \gamma$ - plasmid system under hygromycin B selection (Kemppainen \& Pardo, 2010). The aquaporin cDNA was liberated from the pGEM-T Easy vector with ApaI/PstI, blunt ends were generated with T4 DNA polymerase and the cDNA fragment cloned into SnaBI/StuI-digested pSILBA $\gamma$ between the constitutive Agaricus bisporus gpdII promoter and Aspergillus nidulans $\operatorname{trp} C$ terminator. The correct $\mathrm{cDNA}$ orientation in the expression cassette of pSILBA $\gamma$ was confirmed by sequencing. The full-length pSILBA $\gamma / J Q 585595$-expression vector was cloned as a SacI linearized fragment into the SacI site in the T-DNA of the $\mathrm{pHg}$ binary vector to generate the final $\mathrm{pHg} / \mathrm{pSILBA} \gamma / J Q 585595$ transformation/overexpression construct and the vector was introduced into the Agrobacterium tumefaciens strain AGL1 by electroporation. The L. bicolor UAMH8232 WT strain was transformed with $\mathrm{pHg} / \mathrm{pSILBA} \gamma / J Q 585595$ via Agrobacterium according to Kemppainen etal. (2005) with the following modifications: the fungal colonies were pre-grown on cellophane membranes for $3 \mathrm{~d}$, co-cultivation with Agrobacterium lasted for $3 \mathrm{~d}$ and elimination of Agrobacterium during transformant selection was carried out with $200 \mu \mathrm{g} \mathrm{ml}^{-1}$ of ceftriaxone in the growth medium. To generate the mock transformant strains, L. bicolor UAMH8232 WT was Agro-transformed with pHg/pSILBA $\gamma$. Thirteen and 12 independent transgenic Laccaria strains were obtained for $\mathrm{pHg} /$ pSILBA $\gamma / J Q 585595$ and $\mathrm{pHg} / \mathrm{pSILBA} \gamma$ transformation, respectively. Transformed strains that showed normal phenotypes of the species were selected for further validation.

Southern blot analysis was used to determine transgene copy number. Ten micrograms of gDNA extracted using the DNeasy Plant Maxi Kit (Qiagen) was digested using SacI or BamHI. An 870-bp PCR product was amplified using the 1026-bp hygromycin phosphotransferase gene $(h p h)$ in the binary vector as the template (primers used are reported in Table S1), and used as both positive control and probe. DNA was transferred onto $\mathrm{H}^{+}$-bond membrane (GE Healthcare, Buckinghamshire, UK) using a vacuum blotter (BioRad, Richmond, CA, USA). Probe hybridization, stringent wash and detection reaction were conducted according to the manufacturer's protocol (Amersham
AlkPhos Direct Labeling and Detection System with CDP-Star; GE Healthcare), as previously described (Kemppainen etal., 2008). TAIL-PCR was conducted to identify the T-DNA insertion site in the genome of transgenic strains (Notes S1a; Table S2; Liu, 2012).

\section{Seedling growth and inoculation}

Seeds of Picea glauca (Moench) Voss (National Tree Seed Centre, Canadian Forest Service, Fredericton, NB, Canada) were surface sterilized with $1 \%(\mathrm{v} / \mathrm{v})$ sodium hypochlorite and stratified at $4^{\circ} \mathrm{C}$ according to Groome et al. (1991). Stratified seeds were germinated at $20^{\circ} \mathrm{C}$ on sterile, moistened crepe cellulose paper (Kimpak; Kimberley-Clark, Mississauga, ON, Canada). One week after germination, seedlings were transplanted into autoclaved peat moss : vermiculite $(2: 1)$ in sterilized $170-\mathrm{ml}$ Spencer-Lemaire root trainers (Spencer-Lemaire Industries Ltd, Edmonton, AB, Canada) covered with plastic domes. Seedlings were grown in a controlled environment growth room with $16 \mathrm{~h}$ photoperiod, $22^{\circ} \mathrm{C}: 18^{\circ} \mathrm{C}$ (day: night) temperature, $400 \mu \mathrm{mol}$ $\mathrm{m}^{-2} \mathrm{~s}^{-1}$ photosynthetic photon flux density, and $50-60 \%$ relative humidity.

Laccaria strains were cultured in liquid MMN medium at $20^{\circ} \mathrm{C}$ with shaking at $120 \mathrm{rpm}$ for $4 \mathrm{wk}$. Cultures prepared from the WT strain, one mock strain or two transgenic JQ585595-OE strains (designated $\mathrm{OE} 1$ and $\mathrm{OE} 2$ ) were homogenized in a blender to make liquid inoculum of $\mathrm{OD}_{600}=1.5$. Immediately after transplanting, seedlings were inoculated by injecting $10 \mathrm{ml}$ of homogenized liquid inoculum from one of the four strains described above into the sterilized potting mix. Autoclaved fungal-free liquid MMN was used to treat nonmycorrhizal control seedlings. After 1 month, a second inoculation was conducted by applying $10 \mathrm{ml}$ of the respective inoculum to the soil. Eighteen plants were maintained for each of the five inoculation treatments. Spatial separation of plants minimized the possibility for cross-contamination. Root trainer positions were re-randomized every $3 \mathrm{~d}$ to minimize the impact of any growth chamber heterogeneity.

Two months after the second inoculation, mycorrhizal colonization was examined (Fig. S1; Brundrett et al., 1996).

\section{Measurements of gas exchange, growth, and shoot water potential}

Net photosynthetic and transpiration rates of lateral branches of 3-month-old seedlings were measured between 09:00 h and 12:00 h using a Li-6400 with a $2 \times 3 \mathrm{~cm}^{2}$ red-blue light chamber (Li-Cor, Lincoln, NE, USA). Subsequent to these measurements, needles were collected, scanned and the total surface area of needles calculated using ImageJ (v1.44o; Schneider et al., 2012). Net photosynthetic $\left(P_{\mathrm{n}}\right)$ and transpiration $\left(T_{\mathrm{r}}\right)$ rates were expressed as a function of needle surface area. Measurements were carried out for six plants from each inoculation treatment $(n=6)$. Dry mass was determined after oven drying at $80^{\circ} \mathrm{C}$ for $48 \mathrm{~h}(n=6)$. Terminal shoots of $10-15 \mathrm{~cm}$ in length were excised at noon and immediately placed into a Scholander pressure chamber for 
midday shoot water potential measurements (Scholander et al., 1965) $(n=6)$.

\section{Root hydraulic conductivity}

A high pressure flow meter (HPFM; Tyree et al., 1995) was used to determine whole root hydraulic conductivity $(\mathrm{Lpr})$ of 3 month-old seedlings immediately after gas exchange measurements. The root with soil was removed from the root trainer and kept in a plastic bag submerged in a circulating water bath set to $20^{\circ} \mathrm{C}$ (Thermo Scientific, Hampton, NH, USA) for $30 \mathrm{~min}$ before the first measurement of root hydraulic conductance $\left(K_{\mathrm{r}}\right)$. Increasing pressure was applied to the root to obtain a smooth linear regression between supplied pressure and flow rate. Slope was calculated as $K_{\mathrm{r}}$ value. The temperature of the circulating water bath was then lowered to $10^{\circ} \mathrm{C}$ for $30 \mathrm{~min}$ before the second measurement and to $5^{\circ} \mathrm{C}$ for $30 \mathrm{~min}$ before the final measurement. To determine root volumes, the peat: vermiculite mixture was gently washed off the roots immediately after $K_{\mathrm{r}}$ measurements. Root volumes were determined using the water displacement method; to calculate $L_{\mathrm{pr}}, K_{\mathrm{r}}$ was divided by the root volume (Kamaluddin \& Zwiazek, 2002).

\section{Root cortical cell hydraulic conductivity}

A cell-pressure probe was used to determine the hydraulic conductivity of individual cortical cells $\left(L_{\mathrm{pc}}\right)$ in the roots of 3 -month-old mycorrhizal and nonmycorrhizal P. glauca as previously described (Lee et al., 2010). Roots were collected from six plants per inoculation treatment and kept in a circulating water bath at either 20 or $10^{\circ} \mathrm{C}$ for 30 min before measurement $(n=6)$. A single cortical cell was punctured at a distance of $c .20 \mathrm{~mm}$ from the root tip with a silicon oil-filled micro-capillary. The measurements of hydraulic properties were carried out for c. 20 min and $L_{\mathrm{pc}}$ was calculated (Steudle, 1993).

\section{Quantitative RT-PCR}

Three months after the first inoculation, mycorrhizal and nonmycorrhizal root tip segments of $c .1 \mathrm{~cm}$ in length were collected, stored and ground as described above before total RNA extraction using the RNeasy Plant Mini extraction method (Qiagen), with the addition of $20 \mathrm{mg}$ of polyethylene glycol $8000 \mathrm{ml}^{-1}$ RLT buffer to facilitate the extraction of good quality RNA from the samples. First strand cDNA was synthesized from $1 \mu \mathrm{g}$ total RNA using Superscript II (Life Technologies), and cDNA of $10 \mathrm{ng}^{-1} \mathrm{l}^{-1}$ (in a $2.5-\mu \mathrm{l}$ volume) was used as template for SYBR Green qRT-PCR as described in El Kayal et al. (2011). Primers were designed using Primer Express 3.0 (Applied Biosystems, Life Technologies; Table S1).

\section{Quantification of transgene transcript abundance in JQ585595-OE L. bicolor strains}

Transcript abundance of JQ585595 in transgenic L.bicolor mycelia grown on solid MMN medium at $20^{\circ} \mathrm{C}$ for 3 wk was quantified using the standard curve method of quantification, as previously described (Pfaffl, 2004; El Kayal et al., 2011). Three biological replicates representing independent mycelial cultures were sampled for each strain. Transcript abundance of JQ585595 was normalized against the geometric mean of transcript abundance of reference genes $\alpha$-tubulin (XM_001876554) and translation elongation factor EF2 (XM_001887160), which did not change significantly across all tested samples of mycelia in WT and transgenic strains $(P=0.78)$.

\section{Quantification of transcript abundance of L. bicolor aqu- aporins in mycorrhizal root tips}

Transcript abundance corresponding to the six L. bicolor aquaporins was quantified in roots mycorrhizal with WT, mock and two $\mathrm{OE}$ strains of $L$. bicolor using the standard curve method of absolute quantification (Pfaffl, 2004; El Kayal et al., 2011). EF2 was used as the reference gene, as it exhibited stable expression across all tested samples at 20 and $5^{\circ} \mathrm{C}(P=0.81)$.

\section{Transcript abundance quantification of $P$. glauca PIPs in mycorrhizal and nonmycorrhizal roots}

In order to identify putative P. glauca PIPs, phylogenetic analysis and protein secondary structure prediction were conducted as described in Notes S1b (Johanson etal., 2001; AlmeidaRodriguez etal., 2010). Nine putative PIPs were selected for transcript profiling by qRT-PCR of $P$. glauca roots sampled at $20^{\circ} \mathrm{C}$ and $1 \mathrm{~h}$ after the treatment of placing root trainers in the circulating water bath at $5^{\circ} \mathrm{C}$. PgCDC2 (cell division cycle 2, GQ0197_L17.1, BT106071) was used as the reference gene (Bedon et al., 2009), as its $C_{\mathrm{t}}$ value did not change significantly across all tested samples of mycorrhizal and nonmycorrhizal root tips at 20 and $5^{\circ} \mathrm{C}(P=0.84)$. The relative transcript abundance of these PIPs was calculated using the standard curve method of comparative quantification $\left(\Delta \Delta C_{\mathrm{t}}\right.$ with efficiency correction) (Livak \& Schmittgen, 2001; Pfaffl, 2004). To assess the impact of mycorrhization on expression levels of these P. glauca PIPs, the cDNA samples of nonmycorrhizal roots harvested at $20^{\circ} \mathrm{C}$ were used as calibrator for ratio calculation. To assess the impact of $5^{\circ} \mathrm{C}$ temperature on expression levels of the PIPs, the corresponding samples at $20^{\circ} \mathrm{C}$ was used as calibrator. To evaluate amplification efficiencies for each primer pair, cDNAs of all samples were pooled to generate a $10 \times$ dilution series used as the template for each pair of primers. The slope of standard curves for the target and reference genes ranged between -3.01 and -3.38 , corresponding to the range of the efficiencies between $114.9 \%$ and $97.8 \%$ used in the efficiency correction of $\Delta \Delta C_{\mathrm{t}}$ values.

\section{Statistical analyses}

Descriptive statistics and ANOVA were conducted using Origin 8.0 (OriginLab, Northampton, MA, USA). Tukey tests were used to compare means for statistically significant differences $(P=0.05)$. 


\section{Results}

\section{Characteristics of aquaporin JQ585595}

Six full-length putative aquaporin cDNAs - designated according to their NCBI accession numbers as JQ585592, JQ585593, JQ585594, JQ585595, JQ585596, and JQ585597 - were cloned from the mycelium of L. bicolor UAMH8232. A previously conducted phylogenetic analysis of fungal major intrinsic proteins (MIPs) demonstrated that JQ585592 grouped with orthodox fungal water channels (Cluster I), JQ585593 grouped with fungal aquaglyceroporins (Cluster II), and JQ585594, JQ585595, JQ585596 and JQ585597 all grouped with facultative fungal aquaporins (Cluster III) (Notes S2; Xu et al., 2013). The placement of each of the L. bicolor aquaporins within these major subfamilies is shown in Fig. S2. Four of these showed significant water transport capacity in the oocyte swelling assay (Fig. 1a). The water permeability coefficient $\left(P_{\mathrm{f}}\right)$ of oocytes microinjected with cRNAs corresponding to JQ585595 was significantly higher than that of oocytes injected with other L. bicolor aquaporins (Fig. 1a).

Transcript abundance profiling by qRT-PCR was carried out for the three facultative fungal aquaporins that showed the greatest water transport capacity (JQ585595, JQ585596 and JQ585597; Fig. 1a), as well as JQ585592 that belonged to the cluster of orthodox fungal water channel. The transcript abundance of JQ585595 was significantly higher than the other three aquaporins (Fig. 1b). JQ585595 showed the greatest similarity to the previously characterized L. bicolor aquaporin 443240 of L. bicolor strain $S 238 \mathrm{~N}$ (L. bicolor genome v2.0, Joint Genome Institute; annotated as 391485 in genome v1.0; Dietz et al., 2011; Notes S3). The deduced amino acid sequence of JQ585595 was 94\% identical to 443240, exhibiting 16 amino acid substitutions over the 312 amino acids of the predicted protein. In silico analysis using TMHMM2.0 showed that JQ585595 exhibited canonical aquaporin secondary structure: six transmembrane domains (TMD) and five loops (A-E) (Fig. 2a), with each of the two NPA (asparagine, proline, alanine) signature motifs locating at Loop B and E, respectively (Fig. 2b), aromatic/Arg sites at TMD2, TMD5 and Loop E as the selective filter, and two termini in cytosol. Loops B and E form a seventh half-transmembrane helix and two NPA motifs form a pore for selective transport. Target $\mathrm{P}$ predicted a plasma membrane subcellular localization. Accordingly, JQ585595 was selected for generating transgenic L. bicolor, in order to investigate the role of mycorrhizal aquaporins in ECM plant water relations.

\section{Analysis of L. bicolor transgenic strains}

Seven L. bicolor strains transformed with JQ585595 overexpression construct under control of the constitutive A. bisporus gpdII promoter (Fig. 3a) were tested for transgene expression by qRTPCR. OE 1 and OE 2 showed the highest levels of JQ585595 transcript abundance, with values c. 1.5-fold higher than WT (Fig. 3b). Transcript abundance of JQ585595 in mock strains as well as OE5 and OE7 strains was slightly lower than that of WT (Fig. 3b). Southern blot analysis using a labeled probe targeting
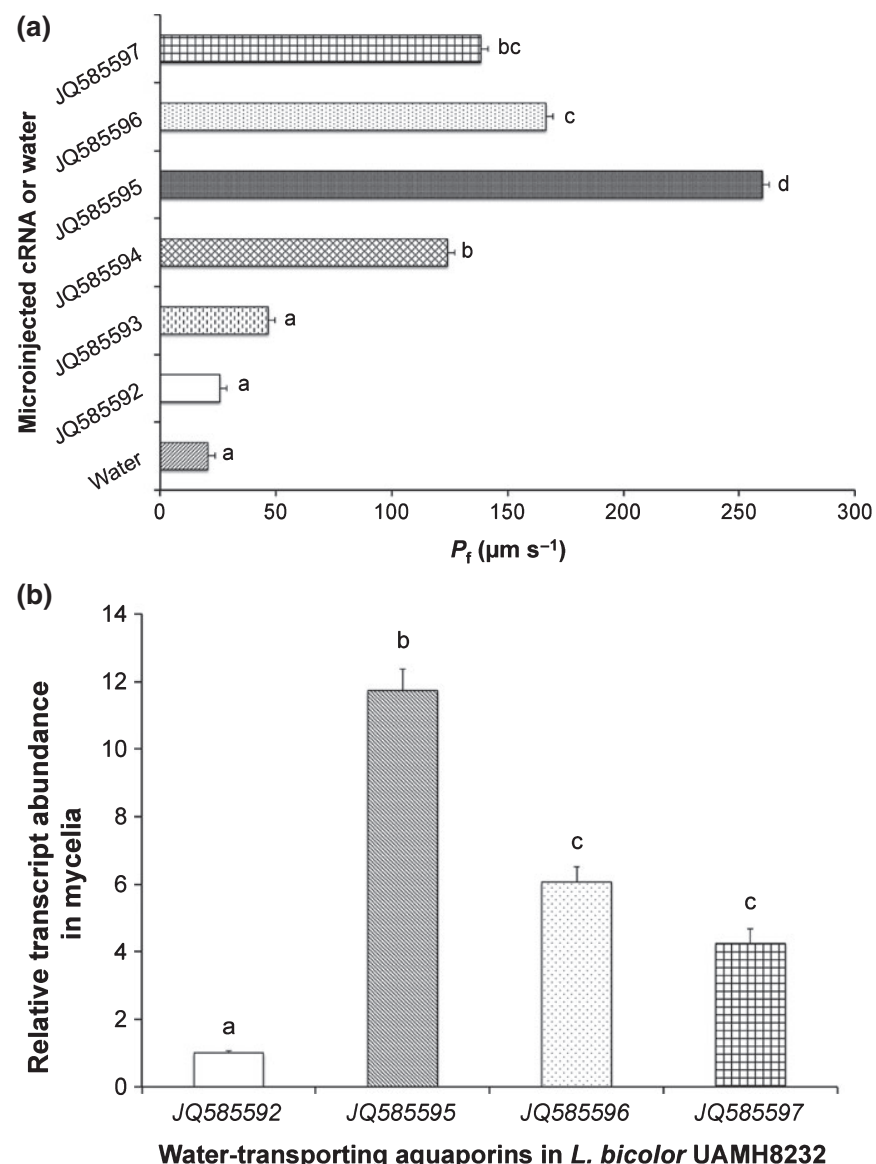

Fig. 1 Functional assay of aquaporins in Laccaria bicolor strain UAMH8232. (a) Osmotic permeability coefficient $\left(P_{f}\right)$ values of Xenopus laevis oocytes in which the corresponding $L$. bicolor aquaporins were heterologously expressed; either CRNAs of each aquaporin gene or water (as negative control) was microinjected into the oocytes. (b) Relative transcript abundance of selected aquaporins in L. bicolor wild-type mycelia measured by a standard curve method of absolute quantification in a qRTPCR assay. The transcript abundance of the aquaporin genes was normalized against the geometric mean of that of the reference genes, $\alpha$-tubulin and EF2. Means, $n=10$ in (a) and 3 in (b) \pm SE are shown. Values with different letters are significantly different at $P \leq 0.05$ (ANOVA, Tukey's test).

the $h p h$ gene confirmed that the OE1, OE2 and Mock 2 strains each harbored a random single insertion of the transgenic cassette (Fig. 3c,d). Using TAIL-PCR, we demonstrated that for all strains, the transgene cassette was inserted into different scaffold locations. None of the insertion sites disrupted ORFs of known genes within the L. bicolor genome (Notes S1a). Based on these analyses, OE1, OE2 and Mock 2 were chosen as the OE strains and mock control, respectively.

\section{Root colonization and impact on seedling growth, gas} exchange and shoot water potentials

All seedlings treated with L. bicolor were successfully inoculated. Evident and similar mantle and Hartig net structures were found in c. $90 \%$ of the 30 sampled root tips from inoculated plants (Fig. S1e-h). There were no significant differences between 
(a)

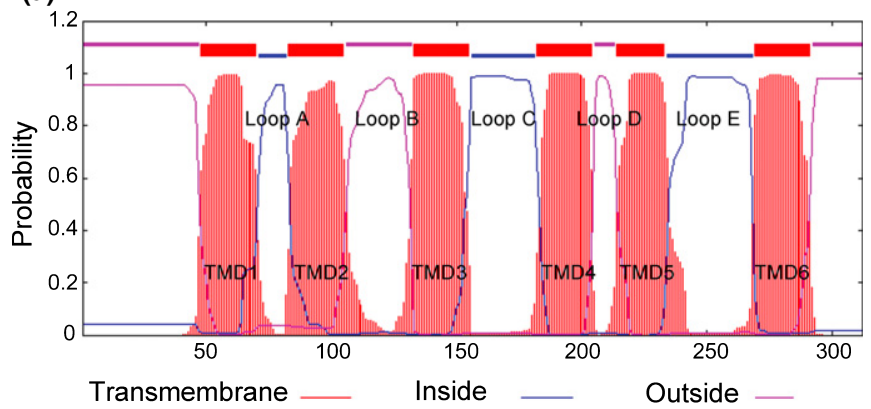

(b)

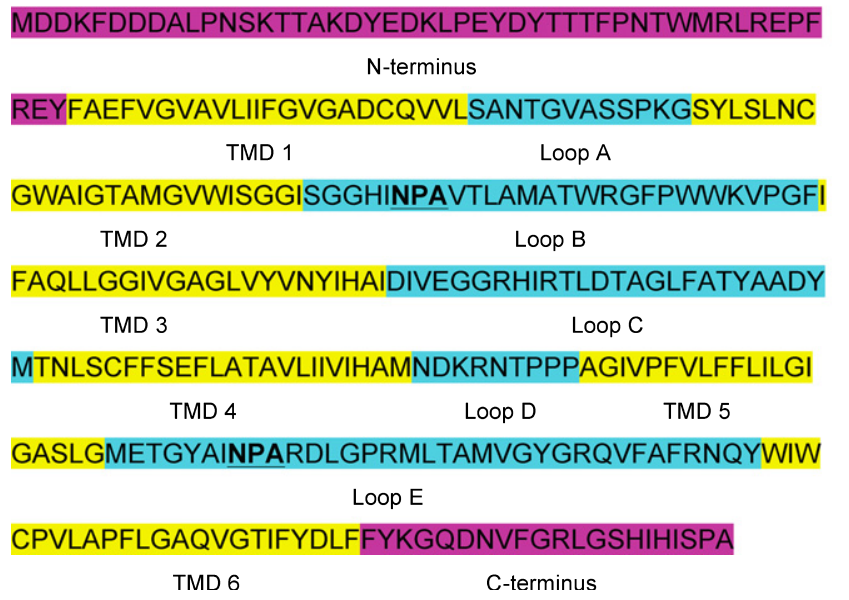

Fig. 2 Deduced amino acid sequence of Laccaria bicolor JQ585595 predicted as a canonical aquaporin with six-transmembrane-domain structure and NPA signature motifs in the in silico assay. (a)

Transmembrane secondary structure of the protein predicted using TMHMM. (b) Deduced amino acid sequence fragments in termini, transmembrane domains TMD 1-6 and Loop A-E, with two NPA motifs (in bold and underlined) in Loop B \& E, respectively.

L. bicolor strains in terms of colonization rates: $93.3 \pm 4.1 \%$ $( \pm \mathrm{SE}$ ), $86.7 \pm 3.3 \%, 90 \pm 4.1 \%$ and $93.3 \pm 4.1 \%$ for WT (Fig. S1e), mock (Fig. S1f), OE1 (Fig. S1g) and OE2 (Fig. S1h), respectively. There was neither extraradical mycelia in soil nor distinct ectomycorrhizal structures in thin sections of the root tips observed in noninoculated plants (Fig. S1i).

Seedlings inoculated with OE1 strain had lower dry mass compared with the noninoculated plants, and both OE1 and OE2 plants also had lower dry mass compared with the mock strain (Fig. 4a). Mycorrhizal plants had higher shoot water potential (Fig. 4b), net photosynthesis (Fig. 4c) and transpiration rates (Fig. 4d) than nonmycorrhizal plants. However, there was no significant difference in these parameters between the different inoculation treatments (Fig. 4).

\section{Fungal aquaporin gene expression in mycorrhizal root tips}

Of the fungal aquaporins, JQ585595 exhibited the highest transcript abundance in mycorrhizal root tips, followed by JQ585593 and JQ585594 (Fig. 5). The transcript abundance levels of JQ585592, JQ585596 and JQ585597 were 5- to 10-fold lower than those of JQ585595.

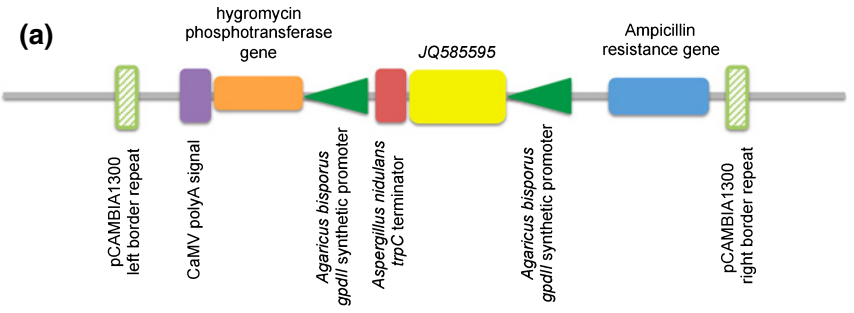

(b)

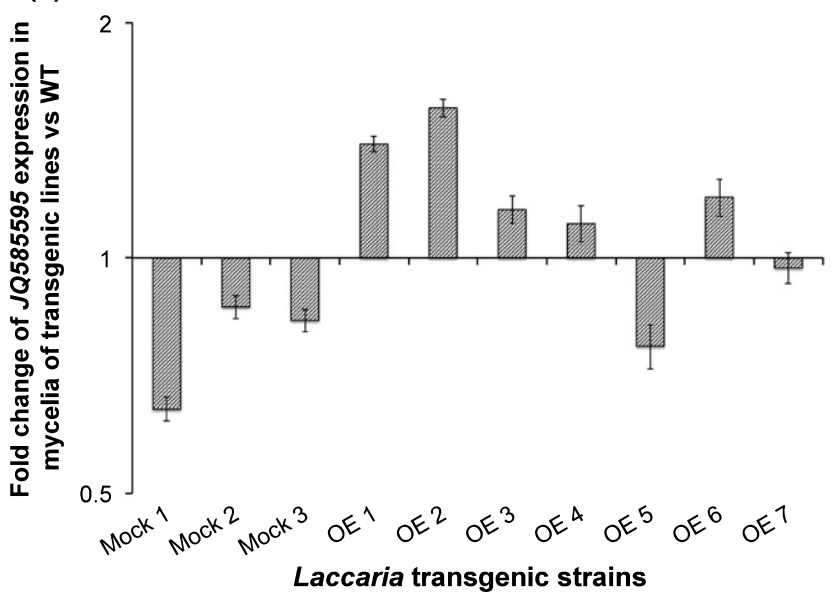

(c) $\begin{array}{lllllllllllllllllll}1 & 2 & 3 & 4 & 5 & 6 & 7 & 8 & 9 & \text { (d) } & 1 & 2 & 3 & 4 & 5 & 6 & 7 & 8 & 9\end{array}$

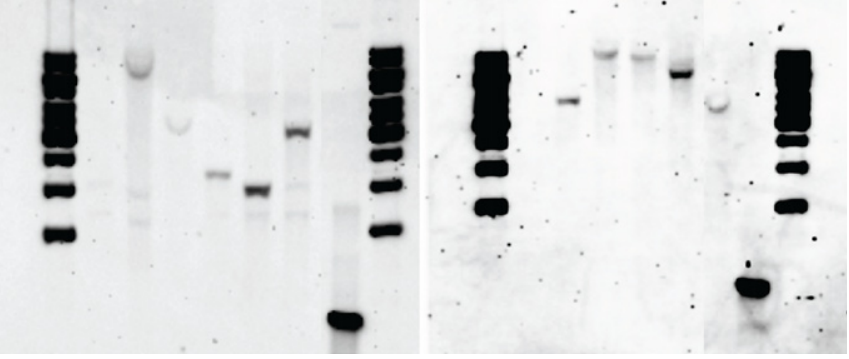

Fig. 3 Construction and selection of Laccaria bicolor transgenic strains overexpressing JQ585595. (a) The transgenic cassette rendering JQ585595 overexpression and hygromycin resistance randomly inserted into the genome of L. bicolor UAMH8232 via Agrobacterium-mediated transformation. (b) The qPCR SYBR-Green assay showing JQ585595 expression in mycelia of the overexpression (OE), mock and wild-type (WT) $(n=3 \pm$ SE). (c, d) Southern blot showing the transgenic strains for single copy insertion events in the genomic DNA digested by Sacl (c) and $\mathrm{BamHI}(\mathrm{d})$; one clear band of hybridization indicating single copy insertion; DNA ladder and digested genomic DNA were loaded in the following order: Lanes 1 and 9, for 1 kb DNA ladder; Lane 2, WT; Lane 3, Mock 1; Lane 4, Mock 2; Lane 5, Mock 3; Lane 6, OE 1; Lane 7, OE 2; Lane 8, $0.2 \mathrm{ng}$ of $870 \mathrm{bp}$ PCR amplicon of hygromycin phosphotransferase gene as positive control. The digested gDNA was purified and denatured before loading for electrophoresis using $0.8 \%$ agarose gel in $0.5 \times$ TBE buffer at $80 \mathrm{~V}$ for $4 \mathrm{~h}$. Chemiluminescence generated via an alkaline phosphatase reaction was detected by $C C D$ sensor using a 30-min exposure time (BioRad ChemiDoc).

The expression of JQ585592 in mycorrhizal root tips was low and not significantly different between the different strains at each examined temperature, and increased in all strains with the decrease in temperature from 20 to $5^{\circ} \mathrm{C} \mathrm{(Fig.} \mathrm{5a).} \mathrm{The} \mathrm{expression}$ of JQ585593 was also low at $20^{\circ} \mathrm{C}$ and not significantly different between mycorrhizal treatments; however, in all strains, it 
(a)
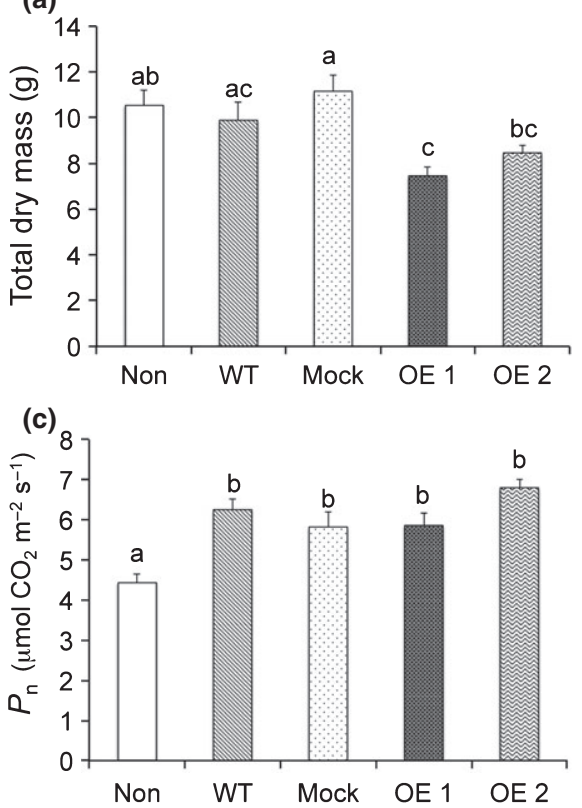

(b)

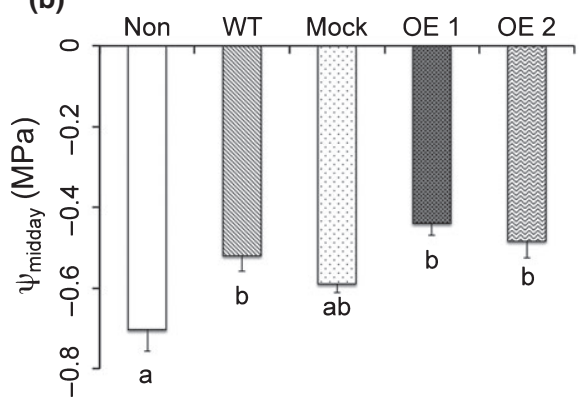

(d)

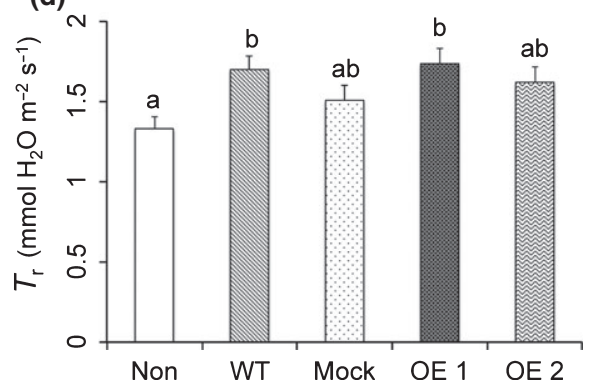

Fig. 4 The effects of mycorrhization with
Laccaria bicolor on (a) total dry mass, (b) midday shoot water potential $\psi_{\text {midday, }}$ (c) net photosynthetic rate $P_{\mathrm{n}}$ and (d) transpiration rate $T_{\mathrm{r}}$ of Picea glauca seedlings. The treatments were nonmycorrhizal (Non), and mycorrhized with wild-type L. bicolor (WT), mock (Mock) and two JQ585595overexpression strains (OE 1 and OE 2). Means $(n=6) \pm$ SE are shown. Different letters indicate significant difference at $P \leq 0.05$ (ANOVA, Tukey's test). increased by more than 10 -fold with the decrease in temperature to $5^{\circ} \mathrm{C}$ (Fig. 5b). Transcript abundance of JQ585594 at $20^{\circ} \mathrm{C}$ was similar in all strains with the exception of a small, but statistically significantly higher level in OE1 compared with the mock strain (Fig. 5c). In all strains, JQ585594 levels were higher at $5^{\circ} \mathrm{C}$ compared with $20^{\circ} \mathrm{C}$ (Fig. 5c). Transcript abundance of JQ585595 was significantly higher in OE strains than in WT and mock strains at $20^{\circ} \mathrm{C}$ (Fig. $5 \mathrm{~d}$ ). In all strains, a decrease in temperature from 20 to $5^{\circ} \mathrm{C}$ induced a significant increase in JQ585595 expression (Fig. 5d). All strains maintained low expression levels of JQ595596 and JQ585597 at 20 and $5^{\circ} \mathrm{C}$ (Fig. 5e,f). Temperature decrease from 20 to $5^{\circ} \mathrm{C}$ had little effect on the expression levels of these aquaporins with the exception of small, but statistically significant decreases observed in OE2 (Fig. 5e,f).

\section{Root hydraulic conductivity $\left(L_{\mathrm{pr}}\right)$ and root cortical cell} hydraulic conductivity $\left(L_{\mathrm{pc}}\right)$

At $20^{\circ} \mathrm{C}, L_{\mathrm{pr}}$ in mycorrhizal seedlings of the WT and mock strains was $c$. 2-fold higher than $L_{\mathrm{pr}}$ in the nonmycorrhizal control seedlings (Fig. 6a). In both OE lines, $L_{\text {pr }}$ was more than $50 \%$ higher than in the WT and mock lines, and c. 3-fold higher compared with nonmycorrhizal control (Fig. 6a).

When root temperature was decreased from $20^{\circ} \mathrm{C}$ first to $10^{\circ} \mathrm{C}$ and then $5^{\circ} \mathrm{C}$, only small decreases in $L_{\mathrm{pr}}$ were measured in nonmycorrhizal plants and in the mock-mycorrhizal plants (Fig. 6a). There was no effect of the decreased temperatures on $L_{\mathrm{pr}}$ in WT plants (Fig. 6a). However, in both $\mathrm{OE}$ lines, the decline in temperature from 20 to $10^{\circ} \mathrm{C}$ and $5^{\circ} \mathrm{C}$ resulted in a greater than two-fold decrease in $L_{\mathrm{pr}}$ (Fig. 6a).

At $20^{\circ} \mathrm{C}, L_{\mathrm{pc}}$ was $c$. 2-fold higher in WT-mycorrhized plants compared with nonmycorrhizal control and more than threefold higher in both OE lines (Fig. 6b). There was no significant effect on $L_{\mathrm{pc}}$ in nonmycorrhizal and WT plants when the temperature was decreased to $10^{\circ} \mathrm{C}$ (Fig. 6b). However, in both $\mathrm{OE}$ lines the decrease in temperature from 20 to $10^{\circ} \mathrm{C}$ lowered $L_{\mathrm{pc}}$ by more than three-fold which brought the $L_{\mathrm{pc}}$ levels to approximately those that were measured in nonmycorrhizal plants (Fig. 6b).

\section{Gene expression of $P$. glauca PIPs in root tips}

Thirteen full-length or near full-length P. glauca PIP cDNAs were identified in a large-scale expressed gene resource (Fig. S3; Notes S2; Rigault et al., 2011). Most of the nine PIPs selected for transcript abundance profiling were represented in sequenced cDNA libraries of P.glauca root tissue, taken as evidence of being expressed in roots (Rigault et al., 2011). In silico analysis showed that the deduced amino acid sequences of the nine putative PIPS that were assayed by qRT-PCR exhibited the canonical aquaporin transmembrane structure (Notes S4). The most highly expressed PIPs among these nine genes in the nonmycorrhizal roots at $20^{\circ} \mathrm{C}$ were GQ03401_M18.1, GQ03703_H07.1 and GQ02905 E13.1, followed by GQ03610_A06.1, GQ03010_E09.1, GQ03001_P18.1 and GQ02901_B20.1. Transcript abundance of GQ03002_G07.1 and GQ03111_E12.1 was low (Fig. S4).

Expression profiles of the nine P. glauca PIPS showed varying responses to mycorrhization with WT, mock, OE1 and OE2 strains. Mycorrhization with WT and mock strains resulted in an three- to four-fold increase in GQ03401_M18.1 transcript abundance, whereas in both OE lines, GQ03401_M18.1 transcript abundance increased by 40- to 56-fold (Fig. 7a). Both OE lines also showed a strong increase in GQ03703_H07.1 expression, whereas the opposite was observed for expression of GQ03610_A06.1 (Fig.7a). Expression of GQ03001_P18.1 was decreased by mycorrhization (Fig. 7a). Transcript abundance of most of the P.glauca PIPS in roots was significantly 
(a)

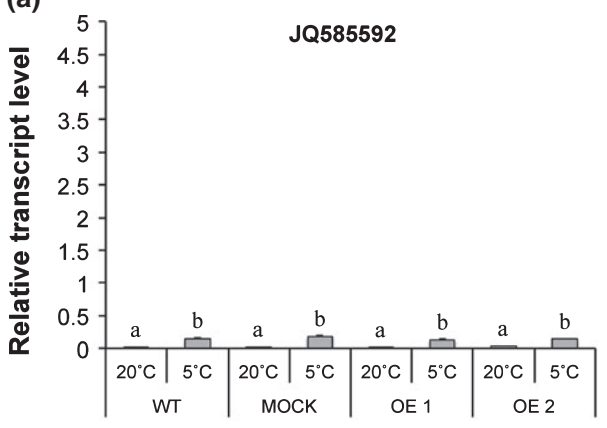

(c)

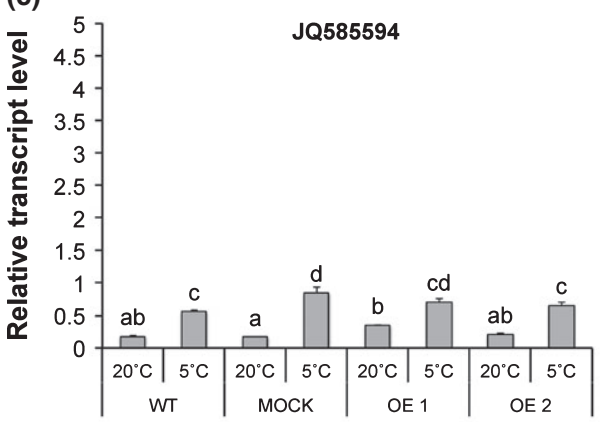

(e)

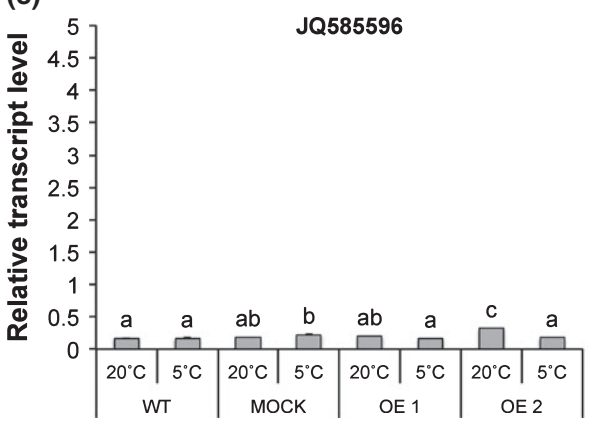

(b)

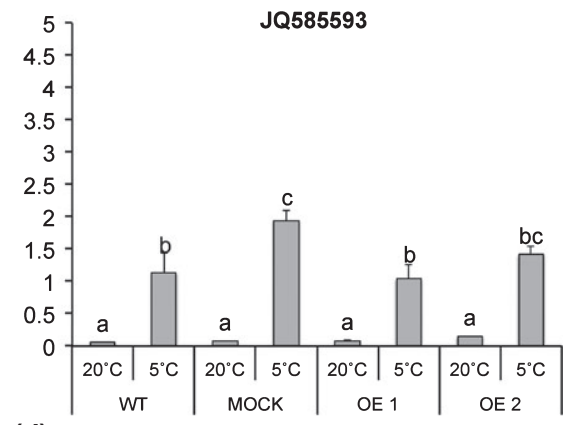

(d)

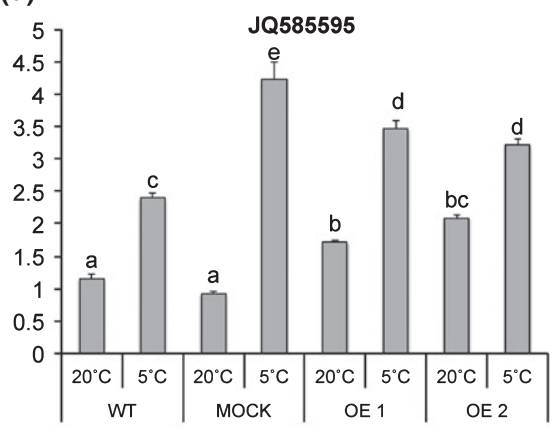

(f)

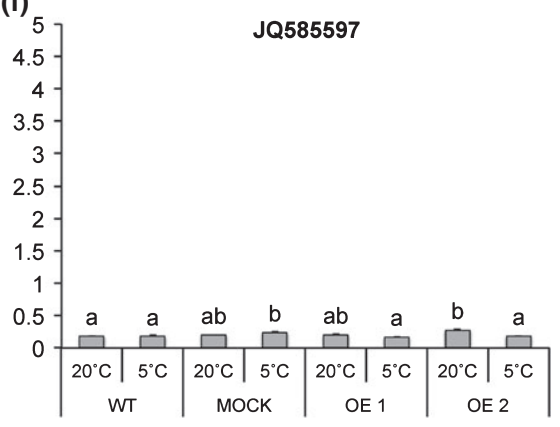

Fig. 5 Relative transcript abundance of Laccaria bicolor aquaporins JQ585592 (a), JQ585593 (b), JQ585594 (c), JQ585595 (d), JQ585596 (e) and JQ585597 (f) in roots of Picea glauca mycorrhized with the wild-type (WT), mock (Mock), and two overexpression (OE 1 and OE 2) strains of L. bicolor and exposed to root temperatures of 20 and $5^{\circ} \mathrm{C}$. The transcript abundance of target aquaporins was normalized to that of the reference gene $E F 2$. Different letters indicate significant differences at $P \leq 0.05$ determined with ANOVA, Tukey's test ( $n=3 \pm \mathrm{SE}$ ). The standard curve template was prepared as a series of dilutions of the mixture of the PCR amplicons of each analyzed gene, with the template concentration ranging from $1.6 \times 10^{2}$ to $1.6 \times 10^{8}$ molecules $\mathrm{ml}^{-1}$ for each gene. The number of molecules was calculated from the mass (ng) and the molecular weight $\left(\mathrm{g} \mathrm{mol}^{-1}\right.$ ) of the PCR amplicons of each gene, given that the fragment size (base pairs) of PCR amplicons was known, and the average molecular weight of each base pair is $660 \mathrm{~g} \mathrm{~mol}^{-1}$ and there is $6.02 \times 10^{23}$ of molecules $\mathrm{mol}^{-1}$. downregulated at $5^{\circ} \mathrm{C}$ compared with $20^{\circ} \mathrm{C}$ in all inoculation treatments (Fig. 7b). With the exception of a higher GQ03610_A06.1 transcript abundance 5 to $20^{\circ} \mathrm{C}$ ratio in both $\mathrm{OE}$ lines compared with the other inoculation treatments, there was no clear pattern showing consistent differences in the temperature responses between the inoculation treatments (Fig. 7b).

\section{Discussion}

Taking advantage of the genome sequence of the L. bicolor model strain S238N (Martin et al., 2008), we obtained six aquaporin genes from L. bicolor UAMH8232. Of these, JQ585595 demonstrated the highest water transport capacity in the heterologous $X$. laevis oocyte expression system, and the highest transcript abundance in mycelium grown on MMN medium. In another study carried out using the same $X$. laevis oocyte assay in the same time frame, JQ585595 demonstrated 40\% higher water-transporting capacity compared to the maize ZmPIP2;8 aquaporin and c. $160 \%$ higher water-transporting capacity than the ZmTIP2;2 aquaporin (Lawrence et al., 2013). JQ585595 shared $94 \%$ amino acid sequence identity with the aquaporin 443240 from v2.0 of the L. bicolor strain S238N genome assembly, equivalent to 391485 from v1.0 (Notes S3). Dietz et al. (2011) demonstrated that the aquaporin 391485 showed relatively high water transport capacity as well as capacity to transport glycerol and ammonia, and that the expression of this aquaporin was upregulated upon mycorrhization with Populus tremuloides grown on MS medium.

Based upon the findings above, we selected JQ585595 for construction of $\mathrm{OE}$ transgenic strains. Similar to earlier studies (Kemppainen et al., 2005, 2008; Kemppainen \& Pardo, 2010), we found that Agrobacterium-meditated transformation was effective in yielding successful L. bicolor transgenic strains. In the transgenic cassette, the constitutive A. bisporus gpdII promoter was used to drive expression of JQ585595 (Fig. 3a). Previous studies have demonstrated the effectiveness of gene expression induced by this promoter in transgenic basidiomycete fungi (Burns et al., 2006; Kilaru et al., 2006; Ding et al., 2011). Compared with WT, the OE strains did not demonstrate a multiplefold increase in transcript abundance for JQ585595 (Fig. 3b), probably because the transcript abundance for the endogenous aquaporin gene was already high in WT grown on MMN 


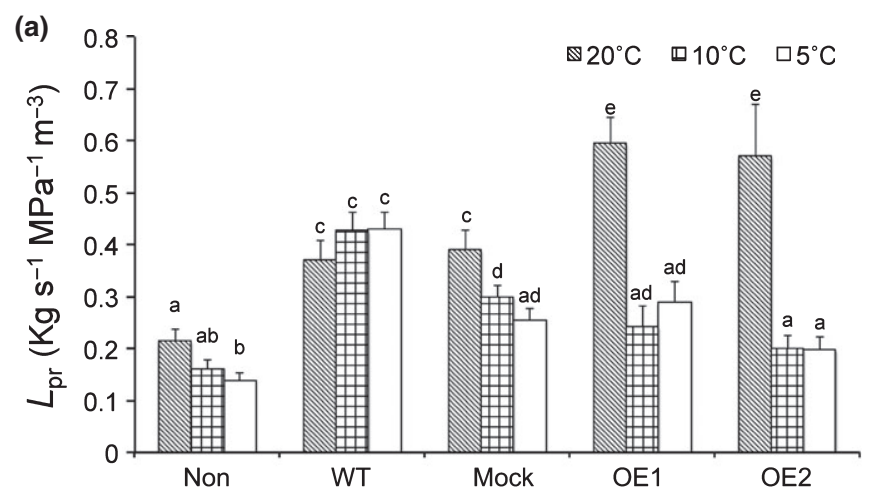

(i)

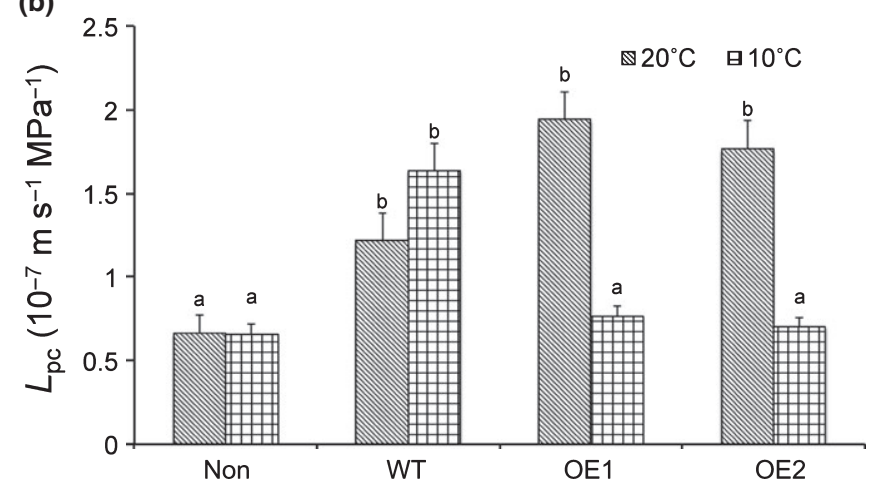

Fig. 6 Root hydraulic conductivity $\left(L_{p r}\right)($ a) and cell hydraulic conductivity of root cortical cells $\left(L_{p c}\right)(b)$ in nonmycorrhizal (Non) Picea glauca seedlings and in seedlings inoculated with the wild-type (WT), mock (Mock), and two overexpression (OE 1 and OE 2) strains of Laccaria bicolor. Means $(n=6) \pm \mathrm{SE}$ are shown. Different letters indicate significant differences at $P \leq 0.05$ (ANOVA, Tukey's test).

medium at $20^{\circ} \mathrm{C}$ (Fig. 1b). Two selected $\mathrm{OE}$ strains demonstrated c. 1.5-fold greater transcript abundance of JQ585595 compared with WT (Fig. 3b). Considering the high expression levels of JQ585595 in WT, the 50-100\% observed increase represents a considerable increase in transcript quantity (Fig. 5d). Importantly, the elevated level of transcript abundance was sufficient to produce significant functional effects (Fig. 6).

In general, the higher expression of JQ585595 in OE strains did not cause significant changes in transcript abundance of other L. bicolor aquaporins at $20^{\circ} \mathrm{C}$ compared with the WT and mock strains, with the exception of JQ585594 in OE1 (Fig. 5c), and JQ585596 and JQ585597 in OE2 (Fig. 5e,f). Transcript profiles of the six L. bicolor aquaporins responded differently to mycorrhizal treatments and temperature decline (Fig. 5). At $20^{\circ} \mathrm{C}$, transcript profiles were not significantly different between $\mathrm{WT}$ and mock strains, indicating that the mock strain behaved as an appropriate control. By contrast, at $5^{\circ} \mathrm{C}$, five of the six L. bicolor aquaporins showed significantly higher transcript abundance in the mock line than WT. We demonstrated using TAIL-PCR that no known ORF was disrupted by the insertion in the mock (Notes S1a; Table S2; Fig. S5); thus, this effect does not appear to be due to unintended interruption of gene function. It remains unclear whether the insertion sites had an impact on gene expression at low temperature via possible mechanisms such as chromatin modification. Interestingly, the enhanced expression of these
L. bicolor aquaporins - especially JQ585595 - in the mock strain at $5^{\circ} \mathrm{C}$ corresponded to a greater decrease in $L_{\mathrm{pr}}$ of mock-inoculated roots at $5^{\circ} \mathrm{C}$ compared to WT-inoculated roots (Fig. 6a). This partly explained why the $L_{\mathrm{pr}}$ profile of mock-inoculated roots was different than that of WT-inoculated roots, but similar to that of the OE-inoculated roots as a function of temperature. The mechanism by which JQ585595 might contribute to this process remains to be explored.

Mycorrhization with OE1 reduced seedling dry mass compared with noninoculated plants. Both OE1- and OE2-inoculated seedlings also showed reduced dry mass compared with mock straininoculated seedlings (Fig. 4a). The effects of mycorrhization on plant growth vary, depending on mycorrhization stage and various abiotic and biotic environmental factors (Smith \& Read, 2008). Growth reductions may occur due to increased carbohydrate demand by the mycorrhizal fungus (Tinker et al., 1994).

Increased net photosynthetic rates of mycorrhizal plants were paralleled by increased transpiration rates (Fig. 4c,d), suggesting that stomatal factors were likely largely responsible for differences in photosynthetic rates. Similar increases in transpiration and photosynthetic rates of mycorrhizal plants were previously reported for ECM and AM associations (Allen et al., 1981; Dosskey et al., 1990; Caravaca et al., 2003; Birhane et al., 2012). In our study, shoot water potentials were higher in mycorrhizal plants despite higher transpiration rates, likely due to higher $L_{\mathrm{pr}}$. Increased shoot water potential and higher rates of gas exchange due to AM mycorrhization were also observed in squash (Cucurbita), soybean (Glycine max) and maize (Zea mays) (Subramanian et al., 1997; Porcel \& Ruiz-Lozano, 2004; Augé et al., 2008). Leaf water potential was stable despite increased transpiration rate in Citrus jambhiri (Levy \& Krikun, 1980). This indicated that water supply to photosynthetic tissues of mycorrhizal plants enabled sufficient stomatal opening for gas exchange to meet the carbon needs of both symbionts.

In the composite model of root water transport, $L_{\mathrm{pr}}$ is a function of apoplastic and cell-to-cell (transmembrane and symplastic) pathways (Steudle \& Peterson, 1998). Water flow follows the least resistance pathway and this resistance is controlled largely by the transmembrane pathway through the transcriptional and posttranslational regulation of PIPS (Törnroth-Horsefield et al., 2006; Maurel et al., 2008). These changes can be determined by the direct measurements of $L_{\mathrm{pc}}$ in root cortical cells (Steudle, 1993; Javot \& Maurel, 2002). In our study, mycorrhization increased $L_{\mathrm{pr}}$ and $L_{\mathrm{pc}}$ by a similar magnitude in $P$. glauca seedlings, suggesting that the decreased resistance of the transmembrane pathway was likely responsible for the increased root water transport capacity. Similar enhancements of $L_{\mathrm{pr}}$ and $L_{\mathrm{pc}}$ were previously reported for mycorrhizal plants and may involve both apoplastic and cell-tocell pathways (Muhsin \& Zwiazek, 2002a,b; Marjanović \& Nehls, 2008; Lee et al., 2010; Bárzana et al., 2012).

Similar to the differences in L. bicolor aquaporin expression observed in WT- and mock-inoculated seedlings, differences in expression of some $P$. glauca aquaporins were observed between WT- and mock-inoculated seedlings. Although expression profiles of L.bicolor aquaporins were not significantly different between OE1 and OE2 mycorrhizal strains, greater differences 
(a)

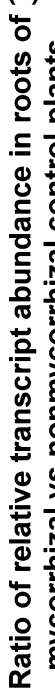

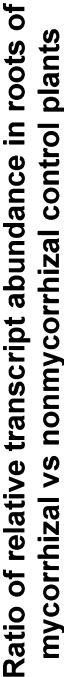

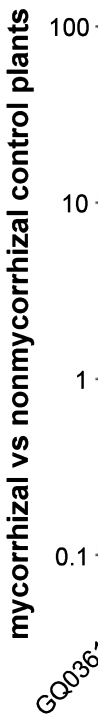

(b)

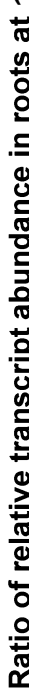

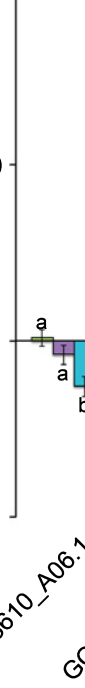

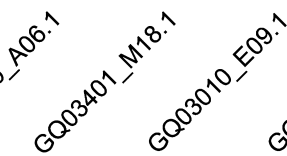

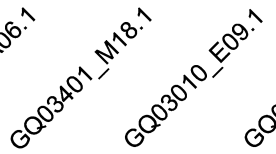

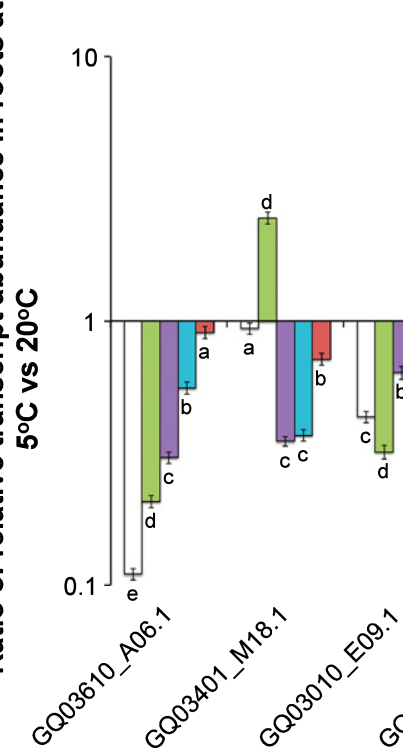

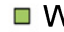

$\square \mathrm{OE}$

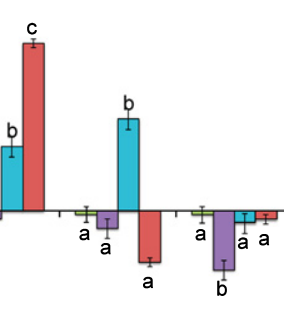

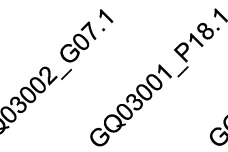

Putative PIPs of Picea glauca
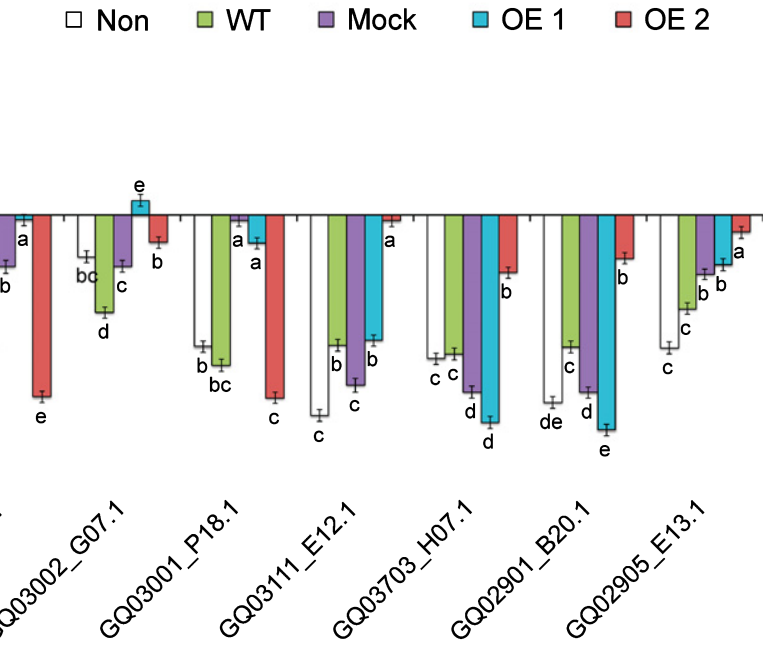

Putative PIPs of Picea glauca
Fig. 7 Changes in transcript abundance of nine putative PIP genes in Picea glauca nonmycorrhizal (Non) root tips and in root tips mycorrhized with the Laccaria bicolor wild-type (WT), mock (Mock), and two overexpression strains (OE1 and OE2) due to (a) mycorrhizal inoculation and (b) temperature decrease from 20 to $5^{\circ} \mathrm{C}$. Relative transcript abundance was measured for three biological replicates in SYBR-Green qPCR assay using a standard curve method of comparative quantification with $P g C D C 2$ as the reference gene. Fold change is displayed on the log scale. Different letters indicate significant differences at $P \leq 0.05$ determined with ANOVA, Tukey's test $(n=3$ $\pm \mathrm{SE})$. were observed between expression profiles of some $P$. glauca aquaporins in OE1- and OE2-inoculated root tips. One possible explanation for these observations is that there may have been differences in fungal-plant dynamics between plants inoculated with OE1 vs OE2. Future studies should include longer-term low temperature treatments and examine root tissue distribution of PIPs in response to temperature to explain the reasons why the expression of some root PIPs was not always consistent between the plants inoculated with different strains.

GQ03401_M18.1 was annotated as PIP1;1 in a recent study of the P. glauca aquaporin gene family (Laur \& Hacke, 2014). The increase in its transcript abundance upon mycorrhization, particularly with OE strains, was accompanied by increased $L_{\mathrm{pc}}$ and $L_{\mathrm{pr}}$ of mycorrhizal P. glauca. PttPIP1;1 and PttPIP2;5 transcript abundance were proposed to be the principal factors responsible for the increase in $L_{\mathrm{pr}}$ of ectomycorrhizal Populus tremula $\times$ tremuloides (Marjanović etal., 2005). However, the signaling pathways leading to this response are not known. Regulation of aquaporin-mediated water transport involves changes in the abundance of aquaporins in cell membranes and aquaporin gating, which is affected by various factors including protein phosphorylation and dephosphorylation (Johansson et al., 1998; Kline et al., 2010), protonation (Tournaire-Roux et al., 2003; Fischer \& Kaldenhoff, 2008), divalent cations (Gerbeau et al., 2002; Verdoucq et al., 2008), trafficking (Prak et al., 2008; Maurel et al., 2009; Zelazny etal., 2009), heteromerization (Fetter et al., 2004), as well as turgor pressure, solute gradients and temperature (Chaumont et al., 2005). Increased water availability in root extracellular space was postulated to be a significant factor triggering PIP transcriptional and post-translational regulation in 
root cells (Steudle \& Peterson, 1998; Javot \& Maurel, 2002). Because the water transporting capacity of mycorrhizal roots increases with the increasing volume of fungal hyphae (Duddridge etal., 1980; Plamboeck etal., 2007), it is plausible that an increase in root hydration by the fungal hyphae may provide a positive feedback mechanism regulating root aquaporin expression and/or function. Additional evidence in support of this hypothesis is provided by the increases at $20^{\circ} \mathrm{C}$ in $L_{\mathrm{pr}}$ and $L_{\mathrm{pc}}$ and in P.glauca PIP GQ03401_M18.1 root expression in OE-inoculated plants compared with the plants mycorrhized with WT and mock strains (Fig. 7a). The expected outcome of JQ585595 fungal aquaporin expression was an increase in the hyphal water flow, likely leading to an increase in hydration at the hyphal-root interphase.

Interestingly, the stimulating effects of the OE mycorrhizas on $L_{\mathrm{pr}}$ and $L_{\mathrm{pc}}$ were totally abolished at low temperatures. Although low soil temperature inhibits root water uptake in most plants, including many boreal tree species (Wan et al., 1999, 2001; Lee etal., 2005, 2012; Aroca et al., 2012), low temperature-tolerant plants, including P. glauca, show little responsiveness of root hydraulic properties to low temperature (Landhäusser et al., 2002). In our study, when temperature was decreased to $10^{\circ} \mathrm{C}, L_{\mathrm{pr}}$ and $L_{\mathrm{pc}}$ were little affected in the nonmycorrhizal and WT-mycorrhizal seedlings. Similar tolerance of $L_{\mathrm{pc}}$ to low temperature was reported for chilling-tolerant figleaf gourd, contrary to chilling-sensitive cucumber (Lee et al., 2005). The responses of $L_{\mathrm{pc}}$ to low temperature have been explained by the aquaporin gene expression and inhibition of aquaporin phosphorylation and/or dephosphorylation (Lee etal., 2005, 2012). In our study, the $L_{\mathrm{pc}}$ in nonmycorrhizal and WT-inoculated plants was not affected despite the reductions in the expression levels of the examined PIPs, pointing to possible gating processes in $P$. glauca being responsible for low temperature tolerance of transmembrane water transport as in figleaf gourd (Lee et al., 2005) and rice (Matsumoto et al., 2009). The overexpression of fungal aquaporin JQ585595 increased the sensitivity of root water transport to low temperature. Because the effect of low root temperature on root hydraulic properties was accompanied by inconsistent differences in root PIP expression compared with the WT and mock lines (Fig. 7b), it is possible that the overexpression of JQ585595 could have affected the root aquaporin gating processes, as previously reported for chilling-sensitive plants (Aroca et al., 2005; Lee et al., 2005, 2012; Murai-Hatano et al., 2008). It is also worth noting that contrary to root P. glauca PIPs, most of the L. bicolor aquaporins exhibited increased transcript abundance when subjected to low temperatures. It can be speculated that the functionality of aquaporin-mediated transport is important to hyphal water transport, and its protection under unfavorable environmental conditions is among the priorities for the fungus.

\section{Conclusions}

Our study has demonstrated the enhancement of $L_{\mathrm{pc}}$ and $L_{\mathrm{pr}}$ in P. glauca roots mycorrhized with L.bicolor overexpressing aquaporin JQ585595. We propose that the contribution of
L. bicolor hyphae to root water transport in P. glauca involves increased apoplastic water transport in the root intercellular spaces, which may lead to increased hydration at the fungal-root interface and, consequently, impact aquaporin expression and cell-to-cell water transport in mycorrhizal roots. During chilling, PIP post-translational regulation may influence $L_{\mathrm{pc}}$ in $P$. glauca roots mycorrhized with L.bicolor strains overexpressing JQ585595, as increased fungal aquaporin transcription may alter hydration in the root intercellular spaces and, consequently, affect root PIP regulation and root hydraulic dynamics.

\section{Acknowledgements}

This research was funded through Natural Sciences and Engineering Research Council of Canada (NSERC) grants to J.J.Z. and J.E.K.C., and through Universidad Nacional de Quilmes (UNQ), Agencia Nacional de Promoción Científica y Tecnológica (ANPCyT) and Consejo Nacional de Investigaciones Científicas y Tecnológicas (CONICET) grants to M.K. and A.G.P. Special thanks to Dr Rheanna Sand for expert guidance on the Xenopus oocyte assays, Dr Warren Gallin and Dr Jonathan Dennis for generously sharing their lab resources and facilities, to Mr Dale Simpson for providing white spruce seeds for this study, to Mr Troy Locke for kindly sharing his knowledge of qRTPCR, to Dr Alfonso Navarro Rodenas for sharing his expertise in mycorrhizal research, and to Ms Arlene Oatway for her expert guidance on microscopy.

\section{References}

Agerer R. 2001. Exploration types of ectomycorrhizae - a proposal to classify ectomycorrhizal mycelial systems according to their patterns of differentiation and putative ecological importance. Mycorrhiza 11: 107-114.

Allen MF. 2007. Mycorrhizal fungi: highways for water and nutrients in arid soils. Vadose Zone Journal 6: 291-297.

Allen MF, Smith WK, Moore TS, Christensen M. 1981. Comparative water relations and photosynthesis of mycorrhizal and non-mycorrhizal Bouteloua gracilis (HBK) Lag. ex Steud. New Phytologist 88: 683-693.

Almeida-Rodriguez AM, Cooke JEK, Yeh F, Zwiazek JJ. 2010. Functional characterization of drought-responsive aquaporins in Populus balsamifera and Populus simonii $\mathrm{x}$ balsamifera clones with different drought resistance strategies. Physiologia Plantarum 140: 321-333.

Aroca R, Amodeo G, Fernández-Illescas S, Herman EM, Chaumont F, Chrispeels MJ. 2005. The role of aquaporins and membrane damage in chilling and hydrogen peroxide induced changes in the hydraulic conductance of maize roots. Plant Physiology 137: 341-353.

Aroca R, Porcel R, Ruiz-Lozano JM. 2007. How does arbuscular mycorrhizal symbiosis regulate root hydraulic properties and plasma membrane aquaporins in Phaseolus vulgaris under drought, cold or salinity stresses? New Phytologist 173: 808-816.

Aroca R, Porcel R, Ruiz-Lozano JM. 2012. Regulation of root water uptake under abiotic stress conditions. Journal of Experimental Botany 63: 43-57.

Augé RM, Toler HD, Sams CE, Nasim G. 2008. Hydraulic conductance and water potential gradients in squash leaves showing mycorrhiza-induced increases in stomatal conductance. Mycorrhiza 18: 115-121.

Bárzana G, Aroca R, Paz JA, Chaumont F, Martinez-Ballesta MC, Carvajal M, Rulz-Lozano JM. 2012. Arbuscular mycorrhizal symbiosis increases relative apoplastic water flow in roots of the host plant under both well-watered and drought stress conditions. Annals of Botany 109: 1009-1017.

Bedon F, Levasseur C, Grima-Pettenati J, Séguin A, MacKay J. 2009. Sequence analysis and functional characterization of the promoter of the Picea glauca 
cinnamyl alcohol dehydrogenase gene in transgenic white spruce plants. Plant Cell Reports 28: 787-800.

Birhane E, Sterck FJ, Fetene M, Bongers F, Kuyper TW. 2012. Arbuscular mycorrhizal fungi enhance photosynthesis, water use efficiency, and growth of Frankincense seedlings under pulsed water availability conditions. Oecologia 169: 895-904.

Brundrett M, Bougher N, Dell B, Grove T, Malajczuk N. 1996. Working with mycorrhizas in forestry and agriculture. Canberra, ACT, Australia: Australian Centre for International Agricultural Research.

Burns C, Leach KM, Elliott TJ, Challen MP, Foster GD, Bailey A. 2006. Evaluation of Agrobacterium-mediated transformation of Agaricus bisporus using a range of promoters linked to hygromycin resistance. Molecular Biotechnology 32: 129-138.

Calvo-Polanco M, Zwiazek JJ, Voicu MC. 2008. Responses of ectomycorrhizal American elm (Ulmus americana) seedlings to salinity and soil compaction. Plant and Soil 308: 189-200.

Cao Y, Anderova M, Crawford NM, Schroeder JI. 1992. Expression of an outward-rectifying potassium channel from maize mRNA and complementary RNA in Xenopus oocytes. Plant Cell 4: 961-969.

Caravaca F, Díaz E, Barea JM, Azcón-Aguilar C, Roldan A. 2003. Photosynthetic and transpiration rates of Olea europaea subsp. sylvestris and Rhamnus lycioides as affected by water deficit and mycorrhiza. Biologia Plantarum 46: 637-639.

Chaumont F, Moshelion M, Daniels MJ. 2005. Regulation of plant aquaporin activity. Biology of the Cell 97: 749-764.

Coleman MD, Bledsoe CS, Smit B. 1990. Root hydraulic conductivity and xylem sap levels of zeatin riboside and abscisic acid in ectomycorrhizal Douglas fir seedlings. New Phytologist 115: 275-284

Dietz S, von Bülow J, Beitz E, Nehls U. 2011. The aquaporin gene family of the ectomycorrhizal fungus Laccaria bicolor: lessons for symbiotic functions. New Phytologist 190: 927-940.

Ding Y, Liang S, Lei J, Chen L, Kothe E, Ma A. 2011. Agrobacterium tumefaciens mediated fused $e g f p$ - $h p h$ gene expression under the control of $g p d$ promoter in Pleurotus ostreatus. Microbiological Research 166: 314-322.

Dominguez I, Itoh K, Sokol SY. 1995. Role of glycogen synthase kinase $3 \mathrm{~b}$ as a negative regulator of dorsoventral axis formation in Xenopus embryos. Proceedings of the National Academy of Sciences, USA 92: 8498-8502.

Dosskey MG, Linderman RG, Boersma L. 1990. Carbon-sink stimulation of photosynthesis in Douglas fir seedlings by some ectomycorrhizas. New Phytologist 115: 269-274.

Duddridge JA, Malibari A, Read DJ. 1980. Structure and function of mycorrhizal rhizomorphs with special reference to their role in water transport. Nature 287: 834-836.

Egerton-Warburton LM, Querejeta JI, Allen MF. 2007. Common mycorrhizal networks provide a potential pathway for the transfer of hydraulically lifted water between plants. Journal of Experimental Botany 58: 1473-1483.

El Kayal W, Allen CCG, Ju CJT, Adams E, King-Jones S, Zaharia LI, Abrams SR, Cooke JE. 2011. Molecular events of apical bud formation in white spruce, Picea glauca. Plant, Cell \& Environment 34: 480-500.

Emanuelsson O, Nielsen H, Brunak S, von Heijne G. 2000. Predicting subcellular localization of proteins based on their $\mathrm{N}$-terminal amino acid sequence. Journal of Molecular Biology 300: 1005-1016.

Felsenstein J. 1985. Confidence limits on phylogenies: an approach using the bootstrap. Evolution 39: 783-791.

Fetter K, Van Wilder V, Moshelion M, Chaumont F. 2004. Interactions between plasma membrane aquaporins modulate their water channel activity. Plant Cell 16: 215-228.

Fischer M, Kaldenhoff R. 2008. On the $\mathrm{pH}$ regulation of plant aquaporins. Journal of Biological Chemistry 283: 33889-33892.

Gambetta GA, Fei J, Rost TL, Knipfer T, Matthews MA, Shackel KA, Walker MA, McElrone AJ. 2013. Water uptake along the length of grapevine fine roots: developmental anatomy, tissue-specific aquaporin expression, and pathways of water transport. Plant Physiology 163: 1254-1265.

Gerbeau P, Amodeo G, Henzler T, Santoni V, Ripoche P, Maurel C. 2002. The water permeability of Arabidopsis plasma membrane is regulated by divalent cations and pH. Plant Journal 30: 71-81.
Giovannetti M, Balestrini R, Volpe V, Guether M, Straub D, Costa A, Ludewig U, Bonfante P. 2012. Two putative-aquaporin genes are differentially expressed during arbuscular mycorrhizal symbiosis in Lotus japonicus. BMC Plant Biology 12: 186.

Groome MC, Axler SR, Gifford DJ. 1991. Hydrolysis of lipid and protein reserves in loblolly pine seeds in relation to protein electrophoretic patterns following imbibition. Physiology Plantarum 83: 99-106.

Javot H, Maurel C. 2002. The role of aquaporins in root water uptake. Annals of Botany 90: 301-313.

Johanson U, Karlsson M, Johansson I, Gustavsson S, Sjovall S, Fraysse L, Weig AR, Kjellbom P. 2001. The complete set of genes encoding major intrinsic proteins in Arabidopsis provides a framework for a new nomenclature for major intrinsic proteins in plants. Plant Physiology 126: 1358-1369.

Johansson I, Karlsson M, Shukla VK, Chrispeels MJ, Larsson C, Kjellbom P. 1998. Water transport activity of the plasma membrane aquaporin PM28A is regulated by phosphorylation. Plant Cell 10: 451-459.

Kamaluddin M, Zwiazek JJ. 2002. Ethylene enhances water transport in hypoxic aspen (Populus tremuloides). Plant Physiology 128: 962-969.

Kemppainen M, Circosta A, Tagu D, Martin F, Pardo AG. 2005. Agrobacterium-mediated transformation of the ectomycorrhizal symbiont Laccaria bicolor S238N. Mycorrhiza 16: 19-22.

Kemppainen M, Duplessis S, Martin F, Pardo AG. 2008. T-DNA insertion, plasmid rescue and integration analysis in the model mycorrhizal fungus Laccaria bicolor. Microbial Biotechnology 1: 258-269.

Kemppainen MJ, Pardo AG. 2010. pHg/pSILBAg vector system for efficient gene silencing in homobasidiomycetes: optimization of ihpRNA - triggering in the mycorrhizal fungus Laccaria bicolor. Microbial Biotechnology 3: 178200.

Khalvati MA, Hu Y, Mozafar A, Schmidhalter U. 2005. Quantification of water uptake by arbuscular mycorrhizal hyphae and its significance for leaf growth, water relations, and gas exchange of barley subjected to drought stress. Plant Biology 7: 706-712.

Kilaru S, Hoegger PJ, Majcherczyk A, Burns C, Shishido K, Bailey A, Foster GD, Kües U. 2006. Expression of laccase gene lccl in Coprinopsis cinerea under control of various basidiomycetous promoters. Applied Microbiology and Biotechnology 71: 200-210.

Kline KG, Barrett-Wilt GA, Sussman MR. 2010. In planta changes in protein phosphorylation induced by the plant hormone abscisic acid. Proceedings of the National Academy of Sciences 107: 15 986-15991.

Krogh A, Larsson B, Von Heijne G, Sonnhammer EL. 2001. Predicting transmembrane protein topology with a hidden Markov model: application to complete genomes. Journal of Molecular Biology 305: 567-580.

Landhäusser SM, Muhsin TM, Zwiazek JJ. 2002. The effect of ectomycorrhizae on water relations in aspen (Populus tremuloides) and white spruce (Picea glauca) at low soil temperatures. Canadian Journal of Botany 80: 684-689.

Larkin MA, Blackshields G, Brown NP, Chenna R, McGettigan PA, McWilliam H, Valentin F, Wallace IM, Wilm A, Lopez R et al. 2007. ClustalW and ClustalX version 2. Bioinformatics 23: 2947-2948.

Laur J, Hacke UG. 2014. Exploring Picea glauca aquaporins in the context of needle water uptake and xylem refilling. New Phytologist 203: 388-400.

Lawrence SD, Novak NG, Xu H, Cooke JEK. 2013. Herbivory of maize by southern corn rootworm induces expression of the major intrinsic protein. Plant Signaling and Behavior 8: e24937.

Lee SH, Calvo-Polanco M, Chung GC, Zwiazek JJ. 2010. Role of aquaporins in root water transport of ectomycorrhizal jack pine (Pinus banksiana) seedlings exposed to $\mathrm{NaCl}$ and fluoride. Plant, Cell \& Environment 33: 769-780.

Lee SH, Chung GC, Jang JY, Ahn SJ, Zwiazek JJ. 2012. Overexpression of PIP2;5 aquaporin alleviates effects of low root temperature on cell hydraulic conductivity and growth in Arabidopsis. Plant Physiology 159: 479-488.

Lee SH, Chung GC, Steudle E. 2005. Gating of aquaporins by low temperature in roots of chilling-sensitive cucumber and chilling-tolerant figleaf gourd. Journal of Experimental Botany 56: 985-995.

Lehto T, Zwiazek JJ. 2011. Ectomycorrhizas and water relations of trees: a review. Mycorrhiza 21: 71-90.

Levy Y, Krikun J. 1980. Effect of vesicular-arbuscular mycorrhiza on Citrus jambhiri water relations. New Phytologist 85: 25-31. 
Li T, Hu Y, Hao Z, Li H, Wang Y, Chen B. 2013. First cloning and characterization of two functional aquaporin genes from an arbuscular mycorrhizal fungus Glomus intraradices. New Phytologist 197: 617-630.

Liu Y. 2012. Calcium-related fungal genes implicated in arbuscular mycorrhiza. $\mathrm{PhD}$ thesis, Huazhong Agricultural University, Wuhan, China, and Burgundy University, Burgundy, France.

Livak KJ, Schmittgen TD. 2001. Analysis of relative gene expression data using real-time quantitative PCR and the $2^{-\Delta \Delta \mathrm{C}(\mathrm{T})}$ method. Methods 25: 402-408.

Marjanović Ž, Nehls U. 2008. Ectomycorrhiza and water transport. In: Varma A, ed. Mycorrhiza. Berlin, Germany: Springer, 149-159.

Marjanović Ž, Uehlein N, Kaldenhoff R, Zwiazek JJ, Weiss M, Hampp R, Nehls U. 2005. Aquaporins in poplar: what a difference a symbiont makes! Planta 222: 258-268.

Martin F, Aerts A, Ahrén D, Brun A, Danchin EG, Duchaussoy F, Gibon J, Kohler A, Lindquist E, Pereda V et al. 2008. The genome of Laccaria bicolor provides insights into mycorrhizal symbiosis. Nature 452: 88-92.

Matsumoto T, Lian HL, Su WA, Tanaka D, Liu CW, Iwasaki I, Kitagawa Y. 2009. Role of the aquaporin PIP1 subfamily in the chilling tolerance of rice. Plant and Cell Physiology 50: 216-229.

Maurel C, Plassard C. 2011. Aquaporins: for more than water at the plantfungus interface? New Phytologist 190: 815-817.

Maurel C, Santoni V, Luu DT, Wudick MM, Verdoucq L. 2009. The cellular dynamics of plant aquaporin expression and functions. Current Opinion in Plant Biology 12: 690-698.

Maurel C, Verdoucq L, Luu D, Santoni V. 2008. Plant aquaporins: membrane channels with multiple integrated functions. Annual Review of Plant Biology 59: 595-624.

Muhsin TM, Zwiazek JJ. 2002a. Ectomycorrhizas increase apoplastic water transport and root hydraulic conductivity in Ulmus americana seedlings. New Phytologist 153: 153-158.

Muhsin TM, Zwiazek JJ. 2002b. Ectomycorrhizae increase water conductance and protect white spruce (Picea glauca) seedlings against salt stress. Plant and Soil 238: 217-225.

Murai-Hatano M, Kuwagata T, Sakurai J, Nonami H, Ahamed A, Nagasuga K, Matsunami T, Fukushi K, Maeshima M, Okada M. 2008. Effect of low root temperature on hydraulic conductivity of rice plants and the possible role of aquaporins. Plant and Cell Physiology 49: 1294-1305.

Nardini A, Salleo S, Tyree MT, Vertovec M. 2000. Influence of the ectomycorrhizas formed by Tuber melanosporum Vitt. on hydraulic conductance and water relations of Quercus ilex L. seedlings. Annuals of Forest Science 57: 305-312.

Navarro-Ródenas A, Bárzana G, Nicolás E, Carra A, Schubert A, Morte A. 2013. Expression analysis of aquaporins from desert truffle mycorrhizal symbiosis reveals a fine-tuned regulation under drought. Molecular Plant-Microbe Interactions 26: 1068-1078.

Navarro-Ródenas A, Ruíz-Lozano JM, Kaldenhoff R, Morte A. 2012. The aquaporin TcAQP1 of the desert truffle Terfezia claveryi is a membrane pore for water and $\mathrm{CO}_{2}$ transport. Molecular Plant-Microbe Interaction 25: 259-266.

Nylund J-E. 1987. The ectomycorrhizal infection zone and its relation to acid polysaccharides of cortical cell walls. New Phytologist 106: 505-516.

Pfaffl MW. 2004. Quantification strategies in real-time PCR. In: Bustin SA, ed. $A-Z$ of quantitative PCR. La Jolla, CA, USA: International University Line (IUL), 87-112.

Pham GH, Kumari R, Singh A, Malla R, Prasad R, Sachdev M, Kaldorf M, Buscot F, Oelmüller R, Hampp R et al. 2004. Axenic culture of symbiotic fungus Piriformospora indica. In: Varma A, Abbott L, Werner D, Hampp R, eds. Plant surface microbiology. Berlin, Germany: Springer, 593-613.

Plamboeck AH, Dawson TE, Egerton-Warburton LM, North M, Bruns TD, Querejeta JI. 2007. Water transfer via ectomycorrhizal fungal hyphae to conifer seedlings. Mycorrhiza 17: 439-447.

Porcel R, Aroca R, Azcón R, Ruiz-Lozano J. 2006. PIP aquaporin gene expression in arbuscular mycorrhizal Glycine max and Lactuca sativa plants in relation to drought stress tolerance. Plant Molecular Biology 60: 389-404.

Porcel R, Ruiz-Lozano JM. 2004. Arbuscular mycorrhizal influence on leaf water potential, solute accumulation, and oxidative stress in soybean plants subjected to drought stress. Journal of Experimental Botany 55: 1743-1750.
Prado K, Maurel C. 2013. Regulation of leaf hydraulics: from molecular to whole plant levels. Frontiers in Plant Science 4: 255.

Prak S, Hem S, Boudet J, Viennois G, Sommerer N, Rossignol M, Maurel C, Santoni V. 2008. Multiple phosphorylations in the C-terminal tail of plant plasma membrane aquaporins: role in subcellular trafficking of AtPIP2; 1 in response to salt stress. Molecular \& Cellular Proteomics 7: 1019-1030.

Rigault P, Boyle B, Lepage P, Cooke JEK, Bousquet J, MacKay JJ. 2011. A white spruce gene catalogue resource for conifer genome analyses. Plant Physiology 157: 14-28.

Saitou N, Nei M. 1987. The neighbor-joining method: a new method for reconstructing phylogenetic trees. Molecular Biology and Evolution 4: 406-425.

Schneider CA, Rasband WS, Eliceiri KW. 2012. NIH Image to ImageJ: 25 years of image analysis. Nature Methods 9: 671-675.

Scholander PF, Bradstreet ED, Hemmingsen EA, Hammel HT. 1965. Sap pressure in vascular plants: negative hydrostatic pressure can be measured in plants. Science 148: 339-346.

Siemens AJ, Zwiazek JJ. 2008. Root hydraulic properties and growth of balsam poplar (Populus balsamifera) mycorrhizal with Hebeloma crustuliniforme and Wilcoxina mikolae var. mikolae. Mycorrhiza 18: 393-401.

Smith SE, Read DJ. 2008. Mycorrhizal symbiosis. Cambridge, UK: Academic Press.

Steudle E. 1993. Pressure probe techniques: basic principles and application to studies of water and solute relations at the cell, tissue, and organ level. In: Smith JAC, Griffiths H, eds. Water deficits: plant responses from cell to community. Oxford, UK: Bios Scientific Publishers Ltd, 5-36.

Steudle E, Peterson CA. 1998. How does water get through roots? Journal of Experimental Botany 49: 775-788.

Subramanian KS, Charest C, Dwyer LM, Hamilton RI. 1997. Effects of arbuscular mycorrhizae on leaf water potential, sugar content, and P content during drought and recovery of maize. Canadian Journal of Botany 75: 15821591

Tamura K, Peterson D, Peterson N, Stecher G, Nei M, Kumar S. 2011. MEGA5: molecular evolutionary genetics analysis using maximum likelihood, evolutionary distance, and maximum parsimony methods. Molecular Biology and Evolution 28: 2731-2739.

Tinker PB, Durall DM, Jones MD. 1994. Carbon use efficiency in mycorrhizas theory and sample calculations. New Phytologist 128: 115-122.

Törnroth-Horsefield S, Wang Y, Hedfalk K, Johanson U, Karlsson M, Tajkhorshid E, Neutze R, Kjellbom P. 2006. Structural mechanism of plant aquaporin gating. Nature 439: 688-694.

Tournaire-Roux C, Sutka M, Javot H, Gout E, Gerbeau P, Luu DT, Bligny R, Maurel C. 2003. Cytosolic $\mathrm{pH}$ regulates root water transport during anoxic stress through gating of aquaporins. Nature 425: 393-397.

Tyree MT, Patiño S, Bennink J, Alexander J. 1995. Dynamic measurements of roots hydraulic conductance using a high-pressure flowmeter in the laboratory and field. Journal of Experimental Botany 46: 83-94.

Uehlein N, Fileschi K, Eckert M, Bienert GP, Bertl A, Kaldenhoff R. 2007. Arbuscular mycorrhizal symbiosis and plant aquaporin expression. Phytochemistry 68: 122-129.

Unestam T, Sun YP. 1995. Extramatrical structures of hydrophobic and hydrophilic ectomycorrhizal fungi. Mycorrhiza 5: 301-311.

Verdoucq L, Grondin A, Maurel C. 2008. Structure-function analysis of plant aquaporin AtPIP2; 1 gating by divalent cations and protons. Biochemical Journal 415: 409-416.

Wan X, Landhäusser SM, Zwiazek JJ, Lieffers VJ. 1999. Root water flow and growth of aspen (Populus tremuloides) at low root temperatures. Tree Physiology 19: 879-884.

Wan X, Zwiazek JJ, Lieffers VJ, Landhäusser SM. 2001. Hydraulic conductance in aspen (Populus tremuloides) seedlings exposed to low root temperatures. Tree Physiology 21: 691-696.

Weatherley PE. 1982. Water uptake and flow in roots. In: Lange O, Nobel PS, Osmond CB, Ziegler H, eds. Physiological plant ecology II. Berlin, Germany: Springer, 79-109.

Xu H, Cooke JEK, Zwiazek JJ. 2013. Phylogenetic analysis of fungal aquaporins provides insight into their possible role in water transport of mycorrhizal associations. Botany 91: 495-504. 
Yi H, Calvo-Polanco M, MacKinnon MD, Zwiazek JJ. 2008. Responses of ectomycorrhizal Populus tremuloides and Betula papyrifera seedlings to salinity. Environmental and Experimental Botany 62: 357-363.

Zelazny E, Miecielica U, Borst JW, Hemminga MA, Chaumont F. 2009. An $\mathrm{N}$-terminal diacidic motif is required for the trafficking of maize aquaporins ZmPIP2; 4 and ZmPIP2; 5 to the plasma membrane. Plant Journal 57: 346-355.

Zhang R, Verkman AS. 1991. Water and urea permeability properties of Xenopus oocytes: expression of mRNA from toad urinary bladder. American Journal of Physiology 260: C26-C34.

\section{Supporting Information}

Additional supporting information may be found in the online version of this article.

Fig. S1 Ectomycorrhizal association between Picea glauca and Laccaria bicolor was induced.

Fig. S2 Aquaporins of Laccaria bicolor UAMH8232 in the phylogenetic tree of 229 fungal major intrinsic proteins (MIPs) from 88 fungal species representing four phyla.

Fig. S3 Phylogenetic analysis of putative Picea glauca MIPs using 36 MIPs of Arabidopsis thaliana and 57 MIPs of Populus as reference proteins.

Fig. S4 Relative transcript abundance of nine Picea glauca PIPs in nonmycorrhizal root tips at $20^{\circ} \mathrm{C}$.
Fig. S5 Gel electrophoresis of TAIL-PCR products to amplify the part of the T-DNA right border and its flanking sequence from the genome of Laccaria bicolor transgenic strains.

Table S1 Polymerase chain reaction primers used in this study

Table S2 TAIL-PCR conditions

Notes S1 Additional materials and methods.

Notes S2 Deduced amino acid sequences used in phylogenetic analysis on plant MIPs and fungal MIPs.

Notes S3 Alignment of aquaporin amino acid sequences of Laccaria bicolor strain UAMH8232 with their counterpart aquaporins of strain S238N.

Notes S4 In silico protein secondary structure prediction on deduced amino acids of putative PIPs of Picea glauca analyzed in this study.

Please note: Wiley Blackwell are not responsible for the content or functionality of any supporting information supplied by the authors. Any queries (other than missing material) should be directed to the New Phytologist Central Office. 